\title{
LA CONFIGURACION CONSTITUCIONAL DEL DERECHO A LA LIBRE ELECCION DE PROFESION U OFICIO *
}

\author{
POR \\ LEOPOLdo Tolivar Alas \\ Catedrático de Derecho Administrativo
}

SUMARIO: I. INTRODUCCIÓN. - II. EL TRATAMIENTO CONSTITUCIONAL DEL DERECHO A LA LURE ELECCIÓN DE PROFESIÓN U ÓFICIO: 1. La elección profesional y la tipología de derechos. 2. La afinidad con la libertad de empresa.-III. CONTENIDO ESENCIAL Y CONTENIDOS DINÁMICOS DEL DERECHO A LA ELECCIÓN PROFESIONAL: 1. El "Contenido esencial» del derecho: A) El contenido esencial de los derechos constitucionales: B) La determinación del contenido esencial de la libertad profesional. 2. Libertad de ejercicio profesional y reparto de competencias restrictivas: A) Derecho interno y Derecho comunitario europeo en la regulación del ejercicio profesional. B) La titulación para ejercer. 3. Libertad profesional y derechos laborales. 4. Oficios y profesiones ante la

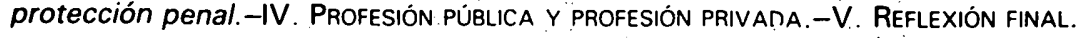

\section{I. . INTRODUCCION}

Contrariamente a lo que algún sector de la doctrina, admirado con la obra de E. Stein (1), con el artículo 12.1 de la Grundgesetz y con sus exégetas (2), pudiera hacernos creer, el derecho a la libre

- Trabajo elaborado para el libro-homenaje al Profesor D. Eduardo García de Enterría.

(1) El libro de Ekkehart STEIN: Derecho Político, publicado en 1971, fue traducido para la Editorial Aguilar por el profesor Sainz Moreno en 1973. Entre los trabajos traducidos al castellano en los que se glosa el derecho a la libre elección de profesión figuran también varios de Frederik A. MAYEK entre los cuales destaca Fundamentos de la libertad, Unión Editorial, 1975.

(2) La doctrina germánica es realmente copiosa en cuanto a monografías sobre el derecho que nos ocupa. Un hito en los comentarios al artículo 12 de la Ley Fundamental de Bonn lo constituye la Freiheit des Berufs. Artikel 12 des Grundgesetzes, de Giesbern UBER Ludwig Appel, Hamburgo, 1952. Posteriormente, Fritz RITTNER: Unternehmen und freier Beruf als Rechtsbegriff, Recht und Staat, Tubinga, 1962. Max WIDMER: Die Gewerbefreheit nach schweizwrischem und die Berufsfreiheit nach deutschem Recht (con importantes conexiones entre el Derecho alemán y el helvético), Verlag Stámpfli \& Cie, Berna, 1967. Christian STARCK: Grundgesetz und árztliche Berufsordnungen, Nomos Verlagsgesellschaft, Baden-Baden, 1969. Ludwig FRÖHLER en colaboración con S. DANNBECK: Das Berufszulassungsrecht der Handwerksordnung. Handwerksrechtsinstitut, Munich, 1971. Un estudio de sociología política lo encontramos en el trabajo de H. A. HESSE: Berufe im wandel (2). F. Enke Verlag. Stuttgart, 197.2. La visión del catedrático de Pedagogía sobre la elección profesional la encontramos en la obra de Walter JAIDE: Die Berufswahl, Juventa Verlag. Munich, 1966; para este autor existirían dos tipos de elección, uno inicial, el cómo se encuentra un trabajo, y otro más vocacional, selectivo, basado ya en una motivación de impulso y preferencia personal (pp. 142 y ss). Otra interesante monografia jurídica -con referencias anticipadas a España, pp. 332 y ss.- la encontramos en el libro de Rupert STADLER: Die Berufsfreiheit in der Europäischen Gemeinschaft, tuduv Studie, Munich; 1980. Más recientemente, Illona OSTNER Beruf und Hausarbeit (con referencia a la emancipación laboral de 
elección de profesión u oficio no es figura novedosa en el Derecho público español.

La opción voluntaria a un trabajo determinado no se incluyó en el artículo 35.1 de nuestra vigente Constitución por el mero prurito de varar entre sus líneas un nuevo derecho ya en circulación por otros ordenamientos. Antes bien, nuestro constitucionalismo conoce, casi ininterrumpidamente, desde hace más de un siglo, la libertad de "cada cual» para "elegir su profesión» y "aprenderla como mejor le parezca».

La inclusión entre los derechos constitucionales de la preferencia personal en el empleo puede contemplarse nítidamente en el artículo 12 de la Constitución restauradora de 30 de junio de 1876 . Texto que, de otra parte, sólo se limita a revocar el absurdo de sus precedentes de 1869 y 1873 (3) que reconocían el derecho a la elección de oficio a los extranjeros omitiendo toda referencia a los nacionales que, lógicamente, debía sobreentenderse que no iban a ser de peor condición que los foráneos.

La Constitución canovista será, pues, la primera en formular la libertad de ejercicio que nos ocupa, distinguiendo la opción de los españoles (art. 12) de la extranjeros (art. 2).

El mismo criterio seguirá el Anteproyecto de Constitución de 1929 en sus artículos 26 y 19.2 que, aunque nunca llegaron a ser derecho vigente, en poco diferirán de lo que, dos años más tarde, se imprimirá en la Constitución de la II República.

El texto de 9 de diciembre de 1931 señalará -sin distinción por razón de nacionalidad- que "toda persona es libre de elegir

\footnotetext{
la mujer), Universidad de Munich, 1982. Otro estudio comparativo entre el Derecho alemán y el suizo lo encontramos en Die Konkretisierung der Berufsfreiheit im Arbeitsrecht der Bundesrepublik Deutschland und der Schweiz, de Friedrich Wilhelm RADU Helbing \& Lichtenhahn, BaselStuttgart, 1978. También FRÖHLER L., y MORTEL G.: Die Berufsbildfixierung im Handwerksrecht und die Frage ihrer verfassungrechtlichen Problematik (2 volúmenes) Handwerksrechtsinstitut, Munich, 1979. La conexión entre libertad profesional y derecho al trabajo puede verse en Gerd HOFFMANN: Berufsfreiheit als Grundrecht der Arbeit, Nomos Verlagsgesellschaft, Baden-Baden, 1981. Por su parte, la editorial berlinesa Duncker \& Humblot ha venido publicando diversos trabajos en torno al tema que nos ocupa; entre ellos, Eugen FleISCHMANN: Die freien Berufe im Rechtsstaat, 1970; Arnulf BRANDSTETTER: Der Erlass von Berufsordnungen durch die Kammern der freien Berufe, 1971; Walter LEISNER: Das Berufsbeamtentum im demokratischen Staat, 1975; Hans HEGE: Das Grundrecht der Berufsfreiheit im Sozialstaat, 1977 y Manfred DEGEN Pressefreiheit, Berufsfreiheit, Eigentumsgarantie, 1981.

(3) El artículo 25 de la Constitución de 1 de junio de 1869 señalaba que utodo extranjero podrá establecerse libremente en territorio español, ejercer en él su industria, o dedicarse a cualquiera profesión para cuyo desempeño no exijan las leyes títulos de aptitud expedidos por las autoridades españolas». Dicha redacción fue literalmente adoptada por el Proyecto de Constitución Federal de 1873. Obsérvese que en tan pionero texto se identifican la libertad de empresa y el derecho a la opción profesional, como más tarde hará la Constitución republicana de 1931 y como también, pese a la separación formal de la vigente de 1978 (arts. 35 y 38), relacionará íntimamente el Tribunal Constitucional en la sentencia 83/1984, de 24 de julio. Al ser la vocación comercial e industrial una opción profesional más (titulada o no), no es frecuente en el constitucionalismo comparado una mención detallada -y menos en un mismo artículo- de ambos derechos.
} 
profesión», añadiéndose el reconocimiento de «la libertad de industria y comercio; salvo las limitaciones que, por motivos económicos $y$ sociales de interés general, impongan las leyes».

El régimen de Franco, pese a contar con una Ley Fundamental (la primera) específicamente dedicada al Trabajo, supuso un retroceso en el reconocimiento expreso de la liberiad de elección profesional, ya que tan sólo pueden hallarse, entre las acosiumbradas frases de tono épico, vagas referencias a dicho derecho, eso sí, conectadas al mundo laboral. Así, el Fuero del Trabajo (1938) señalará en el primero de sus posíulados, que uel trabajo es la participación del hombre en la producción mediante el ejercicio voluntariamente prestado de sus facultades intelectuales y manuales, según la personal vocación, en orden al decoro y holgura de su vida y al mejor desarrollo de la economía nacional». El Fuero de los Españoles (1945) manifestará en su artículo 24 que utodos los españoles vienen derecho al trabajo y el deber de ocuparse de alguna actividad socialmente úril».

La vigente Constitución de 1978 retomará la senda centenaria para establecer en el arículo 35.1 que rodos los españoles urienen el deber de trabajar y el derecho al irabajo», así como "a la libre elección de profesión u oficio...». Pero dicho precepto, como viene señalando la doctrina (4), sólo incluye parte de la previsión constitucional en rorno a la regulación profesional, ya que el artículo 36 reserva a la ley "el ejercicio de las profesiones tiruladas". Esta separación, como se insiste por los aurores, no existe en la Ley Fundamental de Bonn que se repura como precedente inmediato para. el constituyente español. Pero tampoco encontramos la mencionada dispersión en la Constitución de la Resiauración (5), que bien rempranamente se refiere a los títulos profesionales, ni aparece, igualmente, en el exhaustivo artículo de la Constitución Miejicana de 1917 (6) ni en el arrículo 51 del Texio portugués de

(4) Cfr. MAUÑoz machado S.; PAREjo alfonso L., y Ruiloba Santana E.: la libertad do ejercicio de la profesión y el problema de las atribuciones de los técnicos titulados, I.E.A.L., Mladrid, 1983, p. 120.

(5) El artículo 12 de la Constitución de 1876 integraba el derecho a la profesión (párrafos primero y tercero) con las competencias educativas del Estado (párrafos segundo y cuarto). EI engarce era, obviamente, la expedición de títulos profesionales. De ahi que el mismo precepto por el que acada cual es libre de elegir su profesión y de aprenderla como mejor le parezcaw establecería la matización de que "al Estado corresponde expedir los títulos profesionales y establecer las condiciones de los que pretendan obtenerlos, y la forma en que han de probar su aptitudn. Aqui nos encontramos ya con la regla general de elección de trabajo, excepcionada por la libertad de ejercicio de determinadas profesiones tituladas sometidas a control público.

(6) El artículo $4 .^{\circ}$ de la Constitución mejicana de 5 de febrero de 1917 es un auténtico compendio de las cuestiones que suscita el derecho a la libre elección de profesión. Cuestiones que aparecen dispersas o ausentes en Leyes fundamentales mucho más modernas, se interrelacionan con éxito en una redacción que por su interés sumo transcribimos: aA ninguna persona podrá impedirse que se dedique a la profesión, industria, comercio o trabajo que le 
1976 (7). En realidad, el tema es mucho más complejo que la mera escisión entre la elección de profesión y el ejercicio de ésta (8), cuestiones sin duda importantes pero que no agotan los ángulos de estudio de uno de los derechos más proclive a engarzarse con otras protecciones constitucionales.

Pensemos, en primer lugar, que la libertad de elección de trabajo -profesión titulada u oficio- supone un acto de voluntariedad, con lo que cualquier tarea coactivamente encomendada sería, en principio, inconstitucional. Existe un deber de trabajar, pero tal carga se diluye al poder excepcionar el obligado su derecho a la elección de la tarea. Sólo caben prestaciones personales impuestas "con arreglo a la ley» (artículo 31.3 de la Constitución Española), comenzando por el servicio militar o el civil sustitutorio (art. $30 \mathrm{CE}$ ). Por otra parte, el trabajo forzado no cabe siquiera como pena o medida de cumplimiento de condena (9), hasta el punto de que el trabajo forzoso para los reclusos sí es amparable ante el Tribunal

acomode, siendo lícitos. El ejercicio de esta libertad sólo podrá vedarse por determinación judicial, cuando se ataquen los derechos de tercero, o por resolución gubernativa, dictada en los términos que marque la ley, cuando se ofendan los derechos de la sociedad. Nadie puede ser privado del producto de su trabajo, sino por resolución judicial.

La ley determinará en cada Estado cuáles son las profesiones que necesitan título para su ejercicio, las condiciones que deban llenarse para obtenerlo y las autoridades que han de expedirlon.

(7) El artículo 51 de la vigente Constitución portuguesa (que mantiene su redacción original de 2 de abril de 1976), bajo la rúbrica "Del Derecho al Trabajo», señala:

«1. Todos tendrán derecho al trabajo.

2. El deber de trabajar será inseparable del derecho al trabajo, excepto para quienes sufran una merma de su capacidad por razón de edad, enfermedad o invalidez.

3. Todos tendrán derecho a escoger libremente su profesión o géneros de trabajo, salvo las restricciones legales impuestas por el interés colectivo o inherente a la capacidad propian.

(8) Cfr. MUÑOZ MACHADO.PAREJO ALFONSO y RUILOBA SANTANA: La libertad de ejercicio de la profesión... op. cit. p. 118. Igualmente son muy interesantes las «Reflexiones sobre la libertad profesional» de F. LOPEZ RAMÓN en Revista de Administración Pública, núm. 100-102, vol. I (pp. 651-682), muy singularmente, pp. 662 y ss. Este trabajo, publicado en 1983, constituye, junto al libro anteriormente citado, una verdadera isla en la literatura jurídica española sobre este derecho. Así, por ejemplo, SAGARDOY BENGOECHEA J. A., en su comentario al artículo 35 de la Constitución (en Comentarios a las Leyes Políticas, dirigidos por O. ALZAGA: Constitución Española de 1978, tomo III, Edersa, Madrid, 1983, pp. 469 y ss.) realiza un amplio e interesante estudio del derecho al trabajo pero no se detiene en el derecho a la elección de profesión. Resulta paradójico que un país con más de un siglo de tradición constitucional en la materia comience ahora a reparar -por mimetismo con la doctrina germánica- en tan sugestivo tema. Tal vez quepa, como disculpa, el tópico de los vaivenes institucionales que impidieron el correcto desarrollo legislativo de las Constituciones. Pero aqui la disculpa resulta difícil ya que, aunque es cierto que nunca se promulgaron regulaciones completas de este derecho opcional, no es menos cierto que todas las Constituciones abundaban pacífica y coincidentemente en el reconocimiento del mismo, por lo que, por una vez, las sublevaciones no tienen la culpa de la penuria doctrinal.

(9) La expresión «con arreglo a la ley» usada para las prestaciones personales por nuestra vigente Constitución no puede por menos que recordarnos la palabras «en virtud de una ley» del artículo 12.1 de la Ley Fundamental de Bonn que, por cierto, no subordina a la ley la obligación de un trabajo determinado cuando se trate de un servicio público normal (art. 12.2). Sobre la referencia al trabajo forzado, vid. LÓPEZ RAMÓN: «Reflexiones...» cit. p. 664. 
Constitucional (art. 28.2 en relación con $53.2 \mathrm{CE}$ ), en tanto que la imposición de una tarea a un inocente trabajador no parece gozar de tan importante tutela (art. 35.1 en concordancia con 53.1 CE). Valga recordar, por cierto, que la Grundgesetz si admite, en su ensalzado artículo 12, el trabajo forzado en caso de kprivación de libertad dispuesta judicialmente».

Pero también debemos acotar, inmediatamente, que el derecho garantizado en la Constitución Española en lo tocante a la libre dedicación laboral «no es el derecho a desarrollar cualquier actividad, sino el de elegir libremente profesión u oficio», de la misma manera que en el tan próximo artículo 38 no se reconoce uel derecho a acometer cualquier empresa, sino sólo el de iniciar y sostener en libertad la actividad empresarial, cuyo ejercicio está disciplinado por normas de muy distinto orden», tal como ha precisado el Tribunal Constitucional en sentencia 83/1984, de 24 de julio. Por tanto, una cosa es que cada cual haga profesionalmente lo que le parezca, incluso como autodidacta la lo que aparentemente apuntaba la Constitución de la Restauración) y otra bien distinta es que, dentro de las profesiones u oficios preestablecidos normativamente $o$, al menos, libremente permitidos, cada uno elija según sus particulares conveniencias o aptitudes. El derecho consagrado en el artículo 35.1 de la Constitución de 1978 se limita obviamente a reconocer esa facultad de elección entre lo que es lícito $y$ no a potenciar el que cualquier actividad sea realizable por todos. Esto último supondría la destipificación del delito de intrusismo previsto en el artículo 321 del Código Penal, lo que obviamente no era el deseo del constituyente, como lo demuestra la tan discutida previsión del artículo 36 sobre los Colegios profesionales. No obstante, conviene recordar que existe un cierto desuso en la persecución de determinadas actividades. En los tiempos que corren, la cartomancia, la quiromancia y el espiritismo han venido a sustituir a la reja penitencial y captan públicamente la clientela con anuncios que embozan dichas artes bajo la «profesión» de parapsicólogo. Más antiguo es el caso de brujos curanderos, para nada ocultos, cuyas consultas abiertas ha venido a incentivar la desorganización de la sanidad pública. $Y$, como último ejemplo entre los muchos existentes, el aún más viejo: el oficio inmemorial de la mujer (hoy, con la igualdad, abierto a otros géneros) que a diario se disfraza en la prensa de masajista o azafata. Naturalmente, el ordenamiento no puede, en muchas ocasiones, regular hasta el último detalle cualquier posible actividad laboral. Ello sería una lucha perdida contra la imaginación humana y, además, atentaría contra el principio de libertad por el que la Constitución (art. 1.1) uautoriza a los ciudadanos a llevar a cabo 
todas aquellas actividades que la ley no prohíba, o cuyo ejercicio no subordine a requisitos o condiciones determinadas» (10). Por ello. si decimos que el derecho a la libre elección de profesión u oficio sólo contempla la elección entre lo factible legalmente, debemos colegir que ula regulación de las distintas profesiones, oficios o actividades empresariales en concreto, no es por tanto una regulación de los derechos constitucionalmente garantizados en los arrículos 35.1 o 38» (11). $Y$ sin que ello, como también ha advertido el Tribunal Constitucional y veremos en detalle más adelante, exonere a la ley de cualquier protagonismo. A la ley sólo correspondería, en principio, la regulación del contenido esencial del derecho a una opción profesional libre, por mandato del artículo 53.1 de la Constitución. También, por expresa reserva del artículo $\mathbf{3 6}$ de la Norma fundamental, debe ser una ley la que discipline el ejercicio de las profesiones tituladas. Pero más problemático. resultaría pensar que cada oficio precisase de una ley que desarrollara su "conteniodo esencial». $Y$ ello tanto porque "no hay un "contenido esencial" constitucionalmente garantizado de cada profesión, oficio o actividad empresarial concretan, según la sentencia constitucional de $2 \&$ de julio de 198\&, como por el hecho de que sería un absurdo, contrario al principio de libertad, el intentar compendiar bajo "numerus clausus" las formas de ganarse la vida los ciudadanos. Pero, justamente, el que no exista una garantía constitucional para cada tipo de ocupación y el que no parezca procedente que exista una ley para cada oficio (12) no quiere decir, sino justo al contrario, "que las regulaciones limitativas queden entregadas al arbitrio de los reglamentos» (13). El principio de libertad si no puede ser desf́igurado por las leyes, con mayor motivo ha de estar a buen recaudo de las disposiciones administrarivas, pues al margen de que los reglamentos no pueden incidir en contenidos esenciales de derechos (recordemos que no existe una garantía constitucional para cada oficio), "el principio de legalidad (14) -artículos 9.3 y 103.1 CE- impide que la Administración dicte normas sin la suficiente habilitación legal» (sentencia constitucio-

(10) Sentencia constitucional $83 / 1984$, de 24 de julio. Fundamento jurídico 3 . $^{\circ}$ Ponente, señor Rubio Llorente.

(11) Sentencia citada en la nota anterior.

(12) La reserva de ley del artículo 36 de la Constitución sólo se extiende al uejercicio de las profesiones tituladas".

(13) Fundamento jurídico $3 .^{\circ}$ de la citada sentencia constitucional $83 / 1984$, de 24 de julio. Esta decisión, afectante al campo farmacéutico nos recuerda también la existencia de una conocida decisión del Tribunal Constitucional Federal de Alemania sobre este mismo sector profesional y que se reitera en el Derecho Político, cit. de E. STEIN.

(14) Sobre el principio de legalidad de la actuación administrativa vid., por todos, E. GARCIA DE ENTERRÍA y Tomás Ramón FERNÁNDEZ: Curso de Derecho Administrativo, I, Civitas, Madrid 1983, pp. 409 y ss. 
nal 83/1984). Por tanto, siguiendo con el mismo parecer del Tribunal Constitucional, habrá profesiones cuyas limitaciones vengan dadas por meras cláusulas legales generales; otras, para su acceso (pensemos en las profesiones públicas) o ejercicio (las tituladas) requerirán de una ley especial, "pero ello no por exigencia de los artículos 35.1 y 38 de la Constitución» sino en razón de otros artículos de ésta donde se imponen reservas de ley específicas.

Tampoco debemos olvidar, tras estas reflexiones, que a la entrada en vigor de la Constitución $-y$ aún hoy en su décimo aniversario- la situación en España no es la querida por un recto entendimiento del principio de libertad, ya que a las reminiscencias de conflictos profesionales de atribuciones (15) se une un reglamentismo notable de buen número de actividades, incluso manuales o mecánicas, auspiciado por unas organizaciones corporativas a las que, paradójicamente, la Constitución ha venido a dar más relevancia (16).

Parece evidente que en el tema que nos ocupa existen pautas constitucionales contradictorias que trataremos de armonizar en las páginas que siguen. En ellas nos detendremos en la posición constitucional del derecho a la libre elección profesional, así como en su auténtico contenido esencial. Posteriormente, examinaremos algunas facetas dinámicas de tal derecho (acceso, ejercicio, promoción, cambio y protección frente al intrusol para, ulteriormente, estudiar la conexión -no sólo sistemática- con el derecho al trabajo. Antes de la reflexión final contemplaremos las modulaciones que presenta la disparidad entre profesión pública (aún más antiguamente protegida por nuestros textos constitucionales) $y$ actividad privada; cometidos no siempre impermeables entre sí como lo demuestra, de un lado, la publicación de oficios privados, la privacidad de funciones públicas (bien conocida de los notarios) y las recientes desregularizaciones de tareas hace bien poco encomendadas a fedatarios públicos (como es el caso de los agentes de Cambio y Bolsa).

(15) Sobre los conflictos de atribuciones profesionales, véase LOPEZ RAMÓN: «Reflexiones sobre la libertad profesional», cit. pp. 651 y ss., y MUÑOZ MACHADO PAREJO y RUILOBA: La libertad de ejercicio de la profesión... cit. pp. 37 y ss., y, especialmente, parte segunda (pp. 233 al final). Más tarde nos referiremos a la reciente jurisprudencia del Tribunal Supremo.

(16) Contémplese la surtida existencia de Colegios para todo tipo de profesiones: administradores de fincas, agentes de seguros, decoradores, delineantes, agentes comerciales, agentes de la propiedad inmobiliaria, gestores administrativos, etc. Incluso meros oficios manuales se hallan sometidos a estrictas regulaciones. Recuérdese también, recientemente, el problema del ejercicio del oficio de entrenador de fútbol por profesionales extranjeros fichados por equipos españoles. 


\section{EL TRATAMIENTO CONSTITUCIONAL DEL DERECHO A LA LIBRE ELECCION DE PROFESION U OFICIO}

\section{La elección profesional y la tipología de derechos}

Como es sabido la libertad profesional aparece incluida (tanto en su reconocimiento -artículo 35- como en la limitación legal de su ejercicio -artículo 36-) dentro de la sección segunda del capítulo II del título I de la Constitución. Nuestra Ley Fundamental, por tanto, incluye bajo la rúbrica «De los derechos y deberes de los ciudadanos» la libertad de ocupación laboral; expresión no siempre acertada ya que dentro de la mencionada sección segunda podemos hallar junto a derechos con su correlativo deber (caso de la relación matrimonial o la función social de la propiedad o el mismo derechoobligación de trabajar), figuras donde más pesa el onus que el beneficium (la milicia, el sostenimiento de cargas públicas...), asi como instituciones ajenas al régimen propio de los deberes (el derecho de fundación, la libertad de empresa). No es éste el lugar para un exhaustivo análisis de los deberes constitucionales (17), cuya específica mención en el artículo 86.1 de la Norma Fundamental (Decretos-leyes) viene dando importantes quebraderos de cabeza a la doctrina y a una bien polémica jurisprudencia constitucional. Sin embargo, conviene apuntar $-y$ sobre ello volveremosla aparente sinrazón que supone el que un artículo -el 35.1contemple por un igual la libertad de profesión y oficio y, posteriormente, las limitaciones para los títulos habilitantes y la regulación de los Colegios Profesionales aparezcan entre los "derechos $y$ deberes de los ciudadanos" y, por contrario, otras organizaciones corporativas (las Cámaras de Comercio, por ejemplo) resultan incluidas entre los «principios rectores del orden social y económico" (artículo 52). Ello no tiene ningún sentido ya que tanto la libertad de profesión u oficio (art. 35.1) como la libertad de empresa (art. 38) gozan del mismo tratamiento constitucional. $Y$, además, como ha señalado Martínez Val, es obvio que el artículo $52 \mathrm{CE}$, referente a otras organizaciones profesionales distintas de los Colegios, e incluido como decimos entre los principios socioeconómicos (capítulo III del título I), «no define, ni aún de lejos, ni se refiere, ni aún por aproximación, a ningún principio posible orientador de tal política» (18).

(17) Cfr. Varela diaz S.: "La idea de deber constitucional» en Revista Española de Derecho Constitucional, núm. 4, 1982, pp. 69 y ss.

(18) MARTiNEZ VAL J. M. ": "Comentario al articulo 52 de la Constitución» en Comentarios a las leyes políticas..., cit. p. 427. 
Pero ciñéndonos a la libertad profesional cabe recordar con Stadler y López Ramón (19) que nos hallamos ante un derecho beneficiado por la cobertura ofrecida por el artículo 53.1 de la Constitución. Es decir, se trata de un derecho que «vincula a todos los Poderes públicos» y que "sólo por ley» (no orgánica, art. 81.1 $\mathrm{CE}$, per exclusionem) que, en ningún caso podrá alterar su contenido esencial, podrá regularse su ejercicio. $Y$ en caso de regulación legal contraria a la Constitución, la libertad profesional puede defenderse, mediante recurso de inconstitucionalidad [art. 53.1 en relación con $161.1, a), C E]$. No cabe, por tanto, protección inicial en vía de amparo. $Y$ decimos inicial porque la opción profesional sí puede, con facilidad, verse aliada al principio de igualdad 0 a cualquier derecho fundamental. Ello sin contar con el dato de que el acceso a profesiones públicas sí es un derecho fundamental (art. 23.2 (CE). Podría decirse que una cosa es la profesión y otra el acceso ulterior a la función pública, pero tal distinción se vuelve inexistente en casos como la carrera militar (Real Decreto 1046/1986, de 26 de mayo), donde el profesional no se hace después funcionario, sino que existe una simultaneidad entre la carrera y la función pública. $Y$ cosa parecida puede decirse de buen número de cometidos públicos que no tienen alternativa en el mercado privado.

Como todos los derechos contenidos en la sección segunda del capítulo II del título I de la Constitución, el derecho a la elección profesional, para ser variado, no requiere de la reforma más rígida de la Constitución (la prevista en el art. 168) como ocurre con los derechos fundamentales, bastando para su alteración la previsión ordinaria del artículo 167. Pero no parece siquiera necesario este recordatorio, ya que, como venimos señalando, la tradición constitucional sobre este tema en casi nada ha variado desde hace más de un siglo.

\section{La afinidad con la libertad de empresa}

La libertad de empresa, 0 , si se prefiere la nomenclatura clásica de nuestro constitucionalismo, la libertad de industria y comercio, guarda una estrecha vinculación con el derecho a la elección de profesión u oficio. No sólo desde el punto de vista pragmático, por el cual la dedicación al mundo de la empresa es una profesión como otra cualquiera, sino también desde la óptica estrictamente constitucional. Así, nuestra Constitución de 1869 (al igual que el Proyecto

(19) R. STADLER: Die Berufsfreiheit..., cit. pp. 332-334. También, LÓPEZ RAMÓN: artículo citado, p. 652. 
Federal de 1873) considerará la libertad profesional y la de establecimiento industrial una misma cosa, si bien, para el caso de profesiones tituladas y partiendo de que el artículo 25 de dicha norma fundamental sólo contemplaba a los extranjeros, el desempeño de las mismas quedaba a merced de la obtención de títulos de aptitud expedidos por las autoridades españolas.

La Constitución de 1876 mantiene unificados los derechos de elección profesional y establecimiento industrial para los extranjeros (art. 2. \%) mientras que para los nacionales sólo contempla el primero de los mismos y la libertad de creación de centros docentes (art. 12).

El texto republicano de 1931, por su parte, refunde para «toda persona» la libertad de elegir profesión y las de industria y comercio (art. 33). El aludido precepto reserva a la Ley, con respecto a estos derechos, las eventuales limitaciones que pudieran imponerse «por motivos económicos y sociales de interés general».

Las Leyes Fundamentales promulgadas tras la guerra civil, tal vez por mantener un atisbo del nacionalsocialismo, prestaron poca o nula atención a la propia iniciativa de los empresarios privados, en detrimento de un Estado que garantizaba la producción nacional y el pleno empleo.

La vigente Constitución, en fin, separa la libertad profesional de la empresarial aunque en términos muy relativos ya que ambos derechos aparecen (arts. 35.1 y 38) bajo el mismo régimen tuitivo de la sección segunda del capítulo II del título I. Por otra parte el Tribunal Constitucional ha venido a participar de esta identidad manifiesta en su sentencia, ya reiterada, de 24 de julio de 1984 .

En el Derecho comparado, debemos recordar que el artículo 31 de la Constitución helvética de 29 de mayo de 1874 garantiza para toda la Confederación la libertad de comercio e industria, reservando a los cantones las prescripciones sobre su ejercicio efectivo que no pueden afectar al principio de libertad de establecimiento (20). Dicho precepto, cuya quinta y última enmienda data de 1947, no contempla, sin embargo, la específica libertad de oficio o profesión. Sí aparece, en cambio, recogido tal derecho en el Proyecto de revisión total de la Constitución suiza, elaborado ya en 1977, cuyo artículo 18 dice simplemente: "cada uno puede elegir libremente su profesión y su lugar de trabajo». EI

(20) Libertad de establecimiento que corresponde a la Confederación por el artículo citado de la Constitución, así como por el 47 que reserva a aquélla la diferencia entre establecimiento y residencia o permanencia (établissement et séjour). Vid. al respecto TOLIVAR ALAS L: Las libertades lingüísticas, I.N.A. P.. Alcalá de Henares, 1987, pp. 47 y ss. En la doctrina del país helvético destaca la obra de Peter SALADIN: Grundrechte im Wandel: die Rechtsprechung des Schweizerichen Bundesgerichts zu den Grundrechten in einer Sich ändernden Umwelt, 3. edición, Stämpli, Berna, 1982, pp. 220 y ss. 
derecho a la libertad de comercio e industria no tiene, a diferencia de lo que ocurre con la libertad de establecimiento, la consideración de «derecho inalienable e imprescriptible», según el Tribunal Federal suizo (sentencia $83 / 1982$ ) (21).

En el. Derecho alemán, aunque la Grundgesetz no recoge expresamente la libertad de empresa, la doctrina la ha venido infiriendo de la correlación entre el derecho al libre desarrollo de la personalidad (art. 2.1) y la propia opción profesional (art. 12.1), ya que el primero de estos derechos opera como cláusula general de protecciön de cualquier libertad, incluso las no expresamente detalladas en la Constitución (posición contemplada por la sentencia del Tribunal Constitucional Federal, de 16 de enero de 1967) (22). Sin embargo, la proximidad del derecho a la libre elección de profesión es tal que no se necesita forzar norma suprema alguna para colegir que el comerciante o el industrial realizan una profesión y que ésta, en su aspecto de opción personal, está tutelada por la cúspide del ordenamiento jurídico.

En este breve repaso por el Derecho comparado sólo cabe añadir que el artículo $4 .^{\circ}$ de la Constitución mejicana reputa como derecho único la elección de profesión, industria y comercio y que la mayoría de las Constituciones de los países más significativos, omiten referencias expresas a la materia que nos ocupa, limitándose en lo sumo (caso de la norma fundamental italiana) a proclamar la libre iniciativa económica.

En suma, pese a los distintos criterios seguidos tanto por el Derecho histórico como por los ordenamientos comparados, la libertad de elegir profesión u oficio no difiere de la especialidad económica que supone la vocación empresarial. Así lo viene a entender, en su política de liberalización de ejercicio, la Comunidad Económica Europea y el propio Tribunal Constitucional español que ha advertido un mismo "contenido esencial» en los artículos 35.1 y 38 de la Ley Fundamental.

\section{CONTENIDO ESENCIAL Y CONTENIDOS DINAMICOS DEL DERECHO A LA ELECCION PROFESIONAL}

\section{El «contenido esencial» del derecho}

Ya hemos recordado que el derecho a la elección profesional aún nó gozando de la suerte procesal de los derechos fundamenta-

(21) Cifr. Michel HOTTELIER-T: La convention européenne des drois de l'homme dans la jurisprudence du Tribunal Fédéral, Payot, Lausana , 1985, pp. 134 y ss. La sentencia citada puede encontrarse en el repertorio "Schweizerisches Zentralblatt für Staats", 1982, pp. 356 y ss.

(22) MUÑoz MACHADO, PAREjo y RUILOBA siguiendo la obra de MAUNZ DR̈IG HERzOG (Grundgesetz Kommentar, I, 2. a edición, Munich, 1981), en La libertad de ejercicio..., cit. .pp. 116 y ss: 
les (art. 53.2 CE) sí deviene de aplicación directa e inmediata, vinculando en forma efectiva a todos los poderes públicos. Su regulación sólo puede hacerse por ley que uen todo caso deberá respetar su contenido esencial» (art. 53.1 CE).

Vamos, en consecuencia, a examinar ahora la noción de contenido esencial de los derechos, en general, para ulteriormente abordar el supuesto particular de este trabajo. De esta forma trataremos de averiguar hasta dónde llega la reserva de ley y en qué casos está habilitada la Administración para dictar normas, así como en qué medida están legitimadas las múltiples normas que disciplinan el mercado profesional.

\section{A) EL CONTENIDO ESENCIAL DE LOS DERECHOS CONSTITUCIONALES}

La delimitación de este concepto es doblemente importante en un ordenamiento como el nuestro que responde a las peculiaridades de un Estado compuesto. De una parte, teniendo en cuenta que todos los españoles gozan de los mismos derechos y obligaciones en cualquier parte del territorio nacional, sin que quepan obstáculos a la libertad de establecimiento (art. $139 \mathrm{CE}$ ) y que al Estado le corresponde la regulación de las condiciones básicas que garanticen la igualdad en el ejercicio de derechos y deberes (art. 149.1.1. ${ }^{a}$ CE) cabe preguntarse si las Comunidades Autónomas tienen vedada toda intervención normativa en cuestiones referentes a derechos. Por otra parte, también está la incógnita del papel del reglamento -tan frecuente en cuestiones profesionales- ante la reserva de ley instituida por la norma fundamental en lo tocante a derechos cívicos.

A ambos interrogantes ha dado ya cumplida respuesta el Tribunal Constitucional al referirse, precisamente, al contenido esencial de los derechos.

En primer lugar, el Tribunal Constitucional viene negando que la reserva de ley (incluso orgánica) excluya la posibilidad de desarrollos reglamentarios (sentencias 77/1985, de 27 de junio, y 108/1986, de 29 de julio) a menos que se den características peculiares por las que la Constitución establezca reservas específicas de ley con la inherente prohibición reglamentaria (23). El reglamento, por tanto, puede ser objeto de remisión, por parte de la Ley, en materia de derechos, siempre que tal mandato uno suponga deferir a la normación del Gobierno el objeto mismo reservado" que no es otro que el desarrollo de un derecho constitucional, «pues no hay ley en la que se pueda dar entrada a

(23) Tal es el caso del Estatuto de Jueces y Magistrados. 
todos los problemas imaginables, muchos de los cuales, podrán tener solución particular y derivada en normas reglamentarias» (24).

Ante este planteamiento resulta imprescindible acotar el contenido esencial o básico de cada derecho, ya que una vez determinado por la ley estatal sí cabrá la remisión de cuestiones secundarias a la norma administrativa. Y, por descontado, la participación legislativa de las Comunidades Autónomas es perfectamente factible siempre que no se incida en ese contenido básico y toda vez que no se perjudiquen, ratione territorii, las condiciones de igualdad en el ejercicio para todos los españoles (sentencia constitucional de 16 de noviembre de 1981).

En muy temprana sentencia -el 8 de abril de 1981- el Tribunal Constitucional precisó las dos vías de entendimiento de la noción de "contenido esencial». Esta decisión, comentada en su día por Parejo Alfonso (25), parte de la existencia de dos vías de aproximación al «contenido esencial». La primera ues tratar de acudir a lo que se suele. llamar la naturaleza jurídica o el modo de concebir o configurar cada derecho». Desde este primer camino,

«... hay que tratar de establecer una relación entre el lenguaje que utilizan las disposiciones normativas y lo que algunos autores han llamado el metalenguaje 0 ideas generales y convicciones generalmente admitidas entre los juristas, los jueces y... los especialistas en Derecho... El tipo abstracto del Derecho es preexistente conceptualmente al momento legislativo, $y$ en este sentido se puede hablar de una recognoscibilidad de ese tipo abstracto en la legislación concreta....

Desde este punto de vista, sigue la sentencia constitucional de 8 de abril de 1981,

"Constituyen el contenido esencial de un Derecho subjetivo aquellas facultades o posibilidades de actuación necesarias para que el derecho sea cognoscible como pertinente al tipo descrito y sin las cuales deja de pertenecer a ese tipo y tiene que pasar a quedar comprendido en otro, desnaturalizándose, por decirlo así.»

(24) Sentencia constitucional 77/1985, de 27 de junio (Fundamento jurídico $14 .{ }^{\circ}$ ), sobre la Ley orgánica del derecho a la educación.

(25) PAREJO ALFONSO: L.: «EI contenido esencial de los derechos fundamentales en la jurisprudencia constitucional: a propósito de la sentencia del Tribunal Constitucional de 8 de abril de 1981 \%, en Revista Española de Derecho Constitucional, núm. 3, 1981, pp. 169 y ss. También LÓPEZ RAMÓN: «Reflexiones...», cit. pp. 661 y ss., y MUÑOZ MACHADO, PAREJO y RUILOBA: La libertad... cit. pp. 126 y ss.

REVISTA DE ESTUDIOS.-3 
La segunda vía ofrecida por el Tribunal Constitucional consiste en aislar los intereses jurídicamente protegidos como «núcleo y médula» de los derechos subjetivos; la delimitación, en suma, de aquel contenido absolutamente necesario para que los intereses jurídicamente protegibles resulten efectivamente protegidos:

«De este modo, se rebasa o se desconoce el contenido esencial cuando el derecho queda sometido a limitaciones que lo hacen impracticable, lo dificultan más allá de lo razonable o lo despojan de la necesaria protección.»

Estos dos caminos propuestos por el Tribunal Constitucional no son alternativos ni excluyentes sino complementarios a la hora de indagar el concreto contenido esencial de cada derecho.

Como se ha señalado por la doctrina científica, el criterio del Tribunal Constitucional español se aproxima enormemente al mantenido por el órgano homólogo de Alemania en lo relativo a la calificación de "carácter absoluto del contenido esencial, pero dentro de cada derecho fundamental» (26); esto es: existe "un límite definitorio de la sustancia nuclear (de los derechos fundamentales) que en ningún caso puede ser traspasado, si bien ese límite es distinto para cada derecho $y$ ha de ser determinado en concreto». También en la propia jurisprudencia germánica existen tesis a favor del carácter relativo del contenido esencial, lo que viene a traducirse en que sólo puede incidirse en dicho contenido cuando una medida afecta a un derecho singular, pudiendo apreciarse entonces si el núcleo del derecho ha sufrido más de lo estrictamente exigible partiendo de la necesidad que motiva dicha medida (27). Esta posición conduce, obviamente, a propiciar y justificar la legitimidad de las inmisiones precisas en el contenido de cada derecho (28).

Volviendo a la doctrina del Tribunal Constitucional español cabría preguntarse cuándo se puede apreciar una lesión del contenido esencial de un derecho, a través de las dos vías apuntadas por dicho órgano jurisdiccional. Siguiendo la óptima síntesis de Parejo Alfonso, habría menoscabo del citado contenido "cuando la imagen del derecho que proyecta su regulación legal no es recognoscible con precisión y en sus rasgos determinantes como perteneciente a la categoría abstracta teórica de dicho derecho o cuando, aun siendo recognoscible como tal, aparece el derecho en la regulación

(26) PÁREJO ALFONSO L.: "El contenido esencial...", cit. p. 186.

(27) Autor y trabajo citados en nota anterior, p. 184, donde sigue la exposición de la obra ya citada de MAUNZ DR̈IG y HERZOG.

(28) Ibidem. 
legal sujeto a limitaciones o dificultades de ejercicio más allá de lo razonable o despojado de la protección necesaria» (29).

\section{B) LA DETERMINACIÓN DEL CONTENIDO ESENCIAL DE LA LIBERTAD PROFE- SIONAL}

El Derecho público alemán acaudala una extraordinaria experiencia y una rica literatura en torno al núcleo de la libertad de profesión. Tal vez los dos hitos más sobresalientes los constituyan, de una parte, la temprana monografía de Giesbert UBER, en la que, por cierto, se plantea por vez primera el problema de los numerus clausus (30) y la sentencia del Tribunal Constitucional Federal, sobre este mismo tema, de 18 de julio de 1972 (31). Pero la doctrina y la jurisprudencia alemanas han llegado ya mucho más lejos en la Wesensgehalts-garantie del derecho a la elección profesional.

El contenido esencial de este derecho está sustraido al legislador ordinario, de acuerdo con lo que prevé el artículo 19.2 de la Ley Fundamental de Bonn y, por descontado, a la Administración. No olvidemos que el ordenamiento germano permite que la regulación de los derechos profesionales se haga "por Ley o en virtud de una Ley» (art. 12.1 GG).

En este contenido esencial hay que incluir, preferentemente, la libertad de elección profesional, categoría distinta del ejercicio, aunque integrante común de la noción de «actividad profesional». Mientras el ejercicio puede limitarse, como ahora veremos, la elección no puede someterse a otra restricción que la "fuerza impediente de la realidad" o si se prefiere, a razones de estricta organización, como ocurre en el conocido supuesto de numerus clausus (32). La elección se entiende que forma parte del libre desenvolvimiento humano, del desarrollo vocacional de la personalidad y por lo tanto, no puede ser sometida a trabas. Ni siquiera alegando saturación profesional, pues ello equivaldría a negar la concurrencia libre $y$ a sepultar las expectativas de los mejores por venir ante los peores ya establecidos.

El ejercicio profesional es la faceta del derecho más susceptible de limitaciones. Esta conclusión de los autores alemanes es bien

(29) PAREJO: «El contenido esencial...», cit. p. 190.

(30) G. UBER: Freiheit des Berufs... cit. pp. 224. Como curiosidad, esta obra pionera de Uber está dedicada a su maestro Ipsen.

(31) Sentencia del Tribunal Constitucional Federal de 18 de julio de 1972 que fúe debidamente comentada por CARRO FERNÁNDEZ-VALMAYOR. J. L., en su obra Polémica y reforma de la Universidad en Alemania, Madrid, 1976.

(32) STEIN. E.: Derecho Político, cit. p. 176. Para este autor la libertad profesional, como modo de realización personal, muestra su arista más pérfilada en un Estado que se reputa social. 
compartida por la Constitución española que expresamente remite a la ley la regulación del ejercicio de profesiones tituladas (art. 36). Entre las eventuales limitaciones que pueden imponerse al ejercicio están las referidas a la competencia o solvencia profesional. Son muchas, en efecto, las profesiones «cuyo ejercicio conlleva graves responsabilidades frente al público en general» (33). Por ello al Estado corresponde exigir el nivel técnico adecuado a los profesionales que evite daños masivos a terceros, surgiendo aquí la duda, perfectamente advertida por López Ramón (34), de si la mera culminación de unos estudios homologados es suficiente garantía para que la sociedad confie en sus profesionales. El Derecho alemán también contempla otras limitaciones, o si se prefiere, otras intervenciones reguladoras en el ejercicio profesional, si bien su necesidad debe ser demostrada caso por caso; entre éstas, se halla la ordenación de las enseñanzas profesionales (desde el aspecto de organización educativa y garantía de la igualdad entre los profesionales y no como protección a los usuarios) y la conservación de otros valores conexos a la actividad desplegada y tutelados también por la Constitución (35).

Vinculada a esta última limitación se halla la noción de «contenidos objetivos del orden socioeconómico" que suponen que en un ordenamiento, como el alemán, donde se preconiza la economía de mercado y, a la par, existe una cláusula de Estado social, los Poderes públicos no pueden incidir en la regulación del ejercicio privado profesional si no es conforme a las reglas del modelo económico de la Ley Fundamental: Es decir: ni se puede eliminar o hacer irreconocible la libertad y concurrencia profesional ni puede el Estado abdicar en favor de las organizaciones representativas cuestiones que afectan social y económicamente a toda la ciudadanía y que exigen tratamientos igualitarios y planificaciones homogéneas.

Pero tal vez la construcción más conocida del Derecho alemán con respecto al contenido esencial del derecho al ejercicio profesional sea la idea de imagen profesional, por la que a cada actividad se la identifica socialmente con una imagen típica, asumida por los ciudadanos, que incluye la función o funciones tradicionales de esa profesión, así como las condiciones de idoneidad, los presupuestos económicos y los límites convencionales de dicha actividad. EI problema de esta uimagen profesional» (que permitiría hablar de un "tipo abstracto de derecho preexistente», parodiando a nuestro Tribunal Constitucional) es que no resulta útil para las profesiones

(33) Cfr. LÓPEZ RAMÓN: «Reflexiones...» cit. p. 682.

(34) Ibidem.

(35) MUÑoz MAChado, PAREJo y RUILoba op. cit., p. 119. 
novedosas o para aquellas que surjen, por razones de especialidad, al desgajarse lo que hasta entonces era una disciplina única.

Centrándonos ya en la consideración que para el ordenamiento jurídico español merece el "contenido esencial» de la libertad profesional, conviene anticipar que el Tribunal Constitucional ha distinguido drásticamente entre elección de profesión y ejercicio de cada actividad concreta. Por ello no es extraño que la sentencia de 24 de julio de 1984 diga rotundamente que

«...es evidente... que no hay un "contenido esencial constitucionalmente garantizado de cada profesión, oficio o actividad empresarial...»

La razón, para el Tribunal, no es otra que la siguiente:

«...el derecho constitucionalmente garantizado en el artículo 35.1 no es el derecho a desarrollar cualquier actividad, sino el de elegir libremente profesión u oficio...»

Por ello la reserva de Ley a que se refiere el artículo 53.1 de la Constitución sólo comprendería a la regulación -respetuosa con el contenido esencial- de la opción profesional.

Como ya hemos analizado en páginas anteriores esto no quiere decir que la Administración pueda reglamentar cuanto le plazca para disciplinar el mercado profesional. El Tribunal Constitucional ha estimado que es el principio general de libertad el que permite afirmar que toda aquella actividad que la Ley no prohíba es lícita, lo que unido al principio de vinculación positiva de la Administración a la Ley, conduce a pensar en la necesidad de una previsión legal. Previsión de distinta amplitud según los casos, pero que no guarda directa relación con lo dispuesto por el artículo 35.1 de la Constitución.

El "contenido esencial» garantizado constitucionalmente debe buscarse en el puro acto de elección libre de la dedicación profesional. Contenido que, entendemos, es prácticamente inmune a cualquier intervencionismo público que intente dirigir la voluntad de los interesados, aduciendo incluso intereses generales frente a los vocacionales privados. La imposibilidad fáctica -las organizaciones selectivas o limitadas por falta de medios materialespodrían ser una excepción. Pero es que, en realidad, el numerus clausus si no fuerza a otra opción (el estudiante inadmitido en un centro que fuese obligado a matricularse en otrol más que afectar a la elección está denegando una opción concreta. Si además se permite repetir el intento, la posible conculcación se diluye al máximo. Por tanto, los límites reservados a la Ley sólo pueden 
referirse a razones imperiosas de organización (carencia de medios de todo orden); no pueden suponer una forzada adscripción a otra dedicación y no deben cerrar perpetuamente la vía de acceso a la profesión inicialmente deseada, ya que cabe presumir que cesadas las imposibilidades materiales, cesa también la intervención selectiva pública.

Tampoco cabría, de acuerdo con la doctrina constitucional antes expuesta, que los Poderes públicos solaparan bajo el numerus clausus una adecuación del mercado de trabajo a las necesidades reales que se demandan. Otras son las vías incentivadoras y no ésta.

Obviamente, cualquier conexión con el siempre engarzable principio de igualdad nos haría ver posibles discriminaciones en el acceso a la profesión cuando se establecieran trabas en razón del sexo, nacimiento, religión o raza. Pero el tema aquí se desnaturaliza ya que la presencia del principio de igualdad permite vías más amplias de defensa, tanto material como procesalmente. $Y$ de otra parte, lo que aquí nos interesa es la actuación de los poderes públicos con respecto a la disciplina de la actividad profesional y no las sugestivas cuestiones que se plantean en las relaciones laborales inter privatos (36) donde la garantía de los derechos constitucionales es más de una vez polémica (37). Igualmente conviene advertir que las posibles discriminaciones en que incurran los Poderes públicos a la hora de regular el acceso a empleos o profesiones públicas (pensemos en la carrera militar de la mujer, regulada por Real Decreto-ley de 22 de febrero de 1988) también se mueven bajo el específico marco del derecho fundamental proclamado en el artículo 23.2 de la Constitución.

Pero volviendo ya a cada profesión u oficio, es obvio que la negativa del Tribunal Constitucional a admitir la existencia de un contenido esencial de cada actividad garantizado con el máximo rango impide pensar que el legislador está atado por la idea alemana de la «imagen profesional» (38). Tal parece que el supremo intérprete de la Constitución se haya desentendido en la sentencia de 24 de julio de 1984 de la noción de «concepto metajurídico» al no querer ahondar en la expresión "profesión u oficio» que el constituyente no incluyó gratuitamente. Es más: podría deducirse que el Tribunal Constitucional considera la determinación de las concretas profesiones u oficios como un tema

(36) Cfr., el interesante libro de GARCIA TORRES y JIMÉNEZ-BLANCO: Derechos fundamentales y relaciones entre particulares, Civitas, Madrid, 1986.

(37) Los ejemplos citados en la obra aludida en la nota anterior, son sumamente interesantes para una posible aceptación de la doctrina alemana sobre la Drittwirkung.

(38) Obra citada en nota núm. 35, p. 128 
infraconstitucional. Puede parecer un tanto excesivo, ya que la eliminación ex lege de determinadas profesiones - -0 de su imagen típica- incidiría en la libertad de elección. Pero la argumentación del Tribunal Constitucional, a propósito de la profesión farmacéutica y las oficinas de dispensación, es clara:

«Son numerosísimas las normas de nuestro Derecho que disciplinan, regulan y limitan el ejercicio de profesiones u oficios, imponiendo para ello multitud de requisitos diversos, entre los que se cuenta... la posesión de un determinado título académico y/o la afiliación a un Colegio profesional. Nada hay, por tanto, en la Constitución que excluya la posibilidad de regular y limitar el establecimiento de oficinas de farmacia, como tampoco nada que impida prohibir que se lleve a cabo fuera de estas oficinas la dispensación al público de especialidades farmacéuticas. pues el legislador puede legítimamente considerar necesaria esta prohibición o aquella regulación para servir otras finalidades que estima deseables.»

No sólo es imposible hallar mención implícita alguna a la inmutabilidad de la profesión farmacéutica, como imagen social consolidada, sino que podría colegirse la accesoriedad de la relación entre farmacéutico y botica, lo que palmariamente destruye un aspecto típico de la profesión $y$, aún hoy, mayoritario como modus vivendi del sector.

Creemos que el Tribunal Constitucional matizará en un futuro esta tajante separación entre elección y ejercicio profesional (como acabó haciéndose por la jurisprudencia alemana), ya que el contenido de la libertad que nos ocupa incluye la opción entre posibilidades ciertas y no entre quimeras dejadas al arbitrio total del legislador. Si ese contenido debe incluir, como se ha señalado con sumo acierto (39), el límite del respeto a los derechos ajenos y la condición de que toda regulación intervencionista se haga con criterios de proporcionalidad y razonabilidad, la diferencia entre la elección de una profesión y en qué consista el ejercicio concreto de la misma no deja de ser muy relativa. Sería lo mismo que aislar del derecho al sufragio el conocimiento de las opciones a votar.

Sin perjuicio de volver sobre el rango de las normas que han de disciplinar los distintos ejercicios profesionales conviene recordar cómo el Tribunal Constitucional, pese a desechar que la esencia de cada profesión forme parte del contenido esencial protegido por el artículo 35.1 de la Constitución, ha apuntado la necesidad de

(39) Por LÓPEZ RAMÓN en «Reflexiones sobre la libertad profesional», cit. 
previsiones -más o menos generales- confiadas al dominio de la Ley. Ello, como venimos diciendo, no por la reserva de ley del artículo 53.1 CE, sino por los principios de libertad y legalidad. Partiendo de esta premisa es oportuno replantearse la duda formulada por la mejor doctrina (40): en materia de ejercicio y competencias profesionales, el panorama del Derecho español parece acomodarse poco a esa conveniencia de previsiones legales; son muchas y muy dispersas las normas reglamentarias casi independientes que regulan materias claramente impropias de tales disposiciones, a tenor de lo dispuesto en la Constitutición (arts. $1.1,9.3$ y 103.1). Cabe, por tanto, preguntarse si a estas normas preconstitucionales se han visto sobrevenidamente afectadas 0 , incluso, directamente derogadas. Aunque parece lógico que la figura abrogatoria tenga sentido "cuando hay una contradicción material o de fondo" palmariamente apreciable entre "los respectivos contenidos de las normas anteriores y la propia Constitución» (41), siguiendo la doctrina constitucional iniciada en la sentencia de 2 de febrero de 1981, en el caso que nos ocupa no parece aceptable la idea de una derogación global de toda norma reglamentaria en materia de ejercicio profesional. Asi lo ha entendido el propio Tribunal Constitucional al examinar la Base XVI, párrafo noveno, de la Ley de Sanidad Nacional de 25 de noviembre de 1944, en su sentencia 83/1984. Se cuestionaba aqui, la constitucionalidad de dicha Ley en lo tocante a la reserva del sector farmacéutico en cuanto a la regulación y limitación de oficinas de dispensación en el territorio nacional, así como en lo relativo a la habilitación general conferida al Gobierno para reglamentar dicho tema. El criterio del Tribunal Constitucional, como en parte hemos visto, es el de entender correcta la regulación y limitación pública del sector (no hay ningún "contenido esencial» de cada profesión), pero considera derogada por la Constitución la remisión general hecha al Gobierno para establecer la regulación y limitación de las oficinas de farmacia. Por tratarse de una derogación y no de una inconstitucionalidad, la superioridad colisoria de la Ley Fundamental sólo se produce «desde la entrada en vigor de ésta, de tal modo que... (los efectos sobre la Ley) no son los propios de la nulidad a radice». De ello se deriva, según el Alto Tribunal, "como consecuencia obligada, que su pérdida de vigencia no arrastra en modo alguno la de las disposiciones producidas a su amparo (...), cuyo control de legalidad y constitucionalidad corresponde a los órganos del Poder Judicial $y$, en especial, a los del orden contencioso-

(40) Vid. por todos, MUÑoz MACHADO, PAREJO y RUILOBA op. cit., p. 124.

(41) Op. loc. cit., p. 125. 
administrativo». Por tanto, los múitiples reglamentos sobre materias profesionales dictados con habilitaciones muy genéricas y sin apenas contar con bases legales para desarrollar, pueden ser enjuiciados en su constitucionalidad o legalidad por la justicia ordinaria, pero salvo manifiesta contradicción con el tenor constitucional (harto difícil, dada la parquedad de la norma suprema) no pueden entenderse derogados en bloque. Ni siquiera -como fue el caso de las oficinas de farmacia- aunque el Tribunal Constitucional declare que la Ley de la que traen remoto sustento ha sido derogada por la correspondiente disposición tercera de la Constitución.

\section{Libertad de ejercicio profesional y reparto de competen- cias restrictivas}

Ya hemos señalado que la libertad profesional no es un derecho estático. Antes bien, abarca la elección de la dedicación, el acceso a la formación y selección, la admisión en condiciones de igualdad (faceta típica del derecho al trabajo), el derecho a la inscripción corporativa cuando ésta es preceptiva y al trato igualitario dentro de dicha organización. $Y$, en fin, también existe una libertad para cambiar de profesión y un derecho a la promoción profesional, así como múltiples derechos frente a terceros: los económicos derivados de la actividad prestada, la no existencia de intrusismo, etc. De todos estos derechos, algunos de los cuales se escapan del campo jurídico-administrativo, sólo la elección profesional está conectada al contenido esencial del tema que nos ocupa; existen otras manifestaciones del derecho al trabajo -también en el art. 35. 1 CE$y$, por último, nos hallamos con derechos conexos a otras protecciones constitucionales (la libertad, la igualdad, el desarrollo humano y profesional), pero sin una específica tutela en la norma fundamental.

Vamos a examinar a continuación las cautelas impuestas a la libertad de ejercicio profesional, comenzando por el marco competencial que posibilita las mencionadas restricciones.

\section{A) DERECHO INTERNO Y DERECHO COMUNITARIO EUROPEO EN LA REgULA- CIÓN DEL EJERCICIO PROFESIONAL}

La libertad de profesión u oficio no es sólo un problema del Derecho interno de los Estados, ni siquiera una cuestión que se haya internacionalizado a partir de las premisas de los artículos 59 y siguientes del Tratado de Roma de 27 de marzo de 1957. La propia Organización de las Naciones Unidas contempló este dere- 
cho en el artículo 23 de la Declaración Universal de los Derechos del Hombre (42). Hoy en día es uno de los más importantes retos de la unidad europea, pese a los múltiples escollos existentes para armonizar los distintos criterios nacionales. Pero comencemos por hablar de la problemática distribución interna de competencias entre el Estado y las Comunidades Autónomas.

\section{a) Derecho interno español}

La Constitución española, en relación con el ejercicio profesionat, se limitó prácticamente a señalar que, por ley, se habría de regular el relativo a las profesiones tituladas (art. 36). Esta reserva de ley, que alcanza a los Colegios profesionales, no incide, según la doctrina del Tribunal Constitucional, en el contenido esencial de la libertad de elección a que se refiere el artículo 35.1 de la norma fundamental. Por ello es muy razonable la pregunta sobre el tipo de ley que puede satisfacer la reserva constitucional; es decir, si se trata de una ley del Estado o pueden, en este tema, ejercer las Comunidades Autónomas libremente sus potestades legislativas (43).

El tema, en principio, no parece sumamente difícil de resolverse, pese a la parquedad constitucional. Por ello podemos resumir que:

- El Estado tiene facultades exclusivas para garantizar el ejercicio no discriminatorio de la libertad de circulación y establecimiento (44) profesional en cualquier parte del territorio nacional (arts. 139.1 y 149.1.1. ${ }^{\circ}$ CE).

- El Estado posee competencia exclusiva para regular las condiciones de obtención, expedición y homologación de títulos académicos y profesionales (art. 149.1.30. ${ }^{\circ} \mathrm{CE}$ ).

- Las Comunidades Autónomas pueden incluir en sus Estatutos atribuciones sobre materias (como es el caso de los Colegios profesionales y otras corporaciones) no atribuidas expresamente por la Constitución al Estado (art. 149.3 CE).

- Según la doctrina del Tribunal Constitucional, la creación de Colegios no es un acto libre e ilimitado, sino que se requiere la voluntad jurídica pública (auto 486/1984). Los Colegios deben ser creados conforme a la ley a la que corresponde su calificación, siendo para la vigente Corporaciones públicas. Al legislador compete definir lo que son profesiones suscep-

(42) Resolución 217 (III) de la Asamblea General, de 10 de diciembre de 1948.

(43) Op. cit., en nota núm. 40 , pp. 135 y ss.

(44) Resulta curioso que la libertad de establecimiento, tan frecuente en las Constituciones europeas, no se recoge específicamente en la sección derechos fundamentales de la Constitución de 1978 que sólo se refiere a la circulación y residencia. Sin embargo, posteriormente, el artículo 139.1, con mala memoria sistemática, se refiere a esta libertad. 
tibles de colegiación y sólo está limitado a instituir un funcionamiento democrático para estas Corporaciones (sentencias $81 / 1985$ y $42 / 1986)$. A los Colegios, mientras sean corporaciones de Derecho público, les será aplicable en determinados supuestos el Derecho administrativo, $y$, en todo caso, cuando se trate de impugnar actos de contenido público (delegados o desconcentrados por la Administración), es aplicable lo dispuesto en el artículo 106.1 de la Constitución sobre control jurisdiccional de la Administración (auto 731/1985).

- Que los Colegios sean públicos o privados (45) sólo puede determinarlo el Estado, ya que, de optarse por la fórmula de Administraciones corporativas, las bases de su régimen jurídico corresponderian a las Cortes Generales, así como la garantía de un tratamiento común de los administrados ante las diversas Administraciones (art. 149.1.18. ${ }^{\circ} \mathrm{CE}$ ), lo que no sería posible de permitir que cada Comunidad Autónoma eligiera el régimen público o privado de sus Colegios.

- Partiendo de estas premisas, es lógica la asunción de competencias sobre Colegios profesionales y ejercicio de las profesiones tituladas por parte de las Comunidades Autónomas. Tal es el caso de Cataluña (art. 9.23 del Estatuto y Ley de Colegios de 17 de diciembre de 1982), País Vasco (art. 10.22 del Estatuto de Autonomía), Andalucía (art. 13.24 EA) o Canarias (art. 34.A.8 EA). Estas competencias pueden extenderse a todos los planos normativos (se habla incluso de atribuciones exclusivas), comenzando por la legislación. Los únicos límites son los ya apuntados de respeto a las bases jurídico-administrativas dictadas por el Estado (que debe decidir el carácter público o privado de los Colegios), a la adecuación al principio de igualdad efectiva de ejercicio y a la competencia reguladora y homologadora de títulos profesionales, que también pertenece al Estado.

- Por su parte, el Estado está legitimado para todos los cometidos que acabamos de citar y, en uso de sus atribuciones básicas, puede dictar normas como el artículo 15 de la

(45) En realidad, como ha señalado Tomás-Ramón FERNÁNDEZ, (Derecho Administrativo, Sindicatos y Autoadministración, I.E.A.L., Madrid, 1972), los Colegios responden al modelo asociativo; son entidades corporativas de base privada que realizan, por delegación o desconcentración, algunas actividades administrativas. La ley de Colegios Profesionales de 13 de febrero de 1974 y la jurisprudencia subsiguiente siguen insistiendo en el carácter de "corporaciones de Derecho público». Un reciente estudio del máximo interés sobre los Colegios profesionales podemos hallarlo en el "Comentario al artículo 36 de la Constitución» por F. SÁINZ MORENO dentro de los Comentarios a las Leyes políticas..., cit., tomo III, 1983, pp. 509 y ss. 
Ley del Proceso Autonómico, de 14 de octubre de 1983. donde se establecen los siguientes principios de orden:

«2. Las Corporaciones de Derecho público representativas de intereses profesionales que existen o se constituyan en el territorio de cada Comunidad Autónoma, ajustarán su organización y competencias a los principios y reglas básicas establecidas en la legislación del Estado para dichas entidades, sin perjuicio de cualesquiera otras competencias que pudiera atribuirles o delegarles la Administración autonómica.

3. Por Ley del Estado podrán constituirse Consejos Generales o Superiores de las Corporaciones... para asumir la representación de los intereses corporativos en el ámbito nacional o internacional. Sin embargo, los acuerdos de los órganos de estas Corporaciones, con competencia en ámbito inferior al nacional, no serán susceptibles de ser recurridas en alzada ante los Consejos Generales o Superiores, salvo que sus Estatutos dispusieran lo contrario.»

- Esta previsión, coherente con los postulados constitucionales que acabamos de exponer sobre el ejercicio profesional y la colegiación, se halla expresamente refrendada por la sentencia constitucional de 5 de agosto de 1983.

Pero al Estado también le corresponde hacer efectivas en todo su territorio las normas sobre derechos y libertades -comenzando por la más célebre Declaración Universal, que contempla el tema de la libertad de elección de trabajo- contenidas en tratados y acuerdos internacionales ratificados por España. Tal es el caso del Tratado de Roma y de su derecho derivado.

b) Derecho comunitario europeo

El Tratado de Roma, de 1957, partió, en el artículo 7, de la prohibición de «toda discriminación por razón de la nacionalidad» $y$ el capítulo III de su título III se destinó exclusivamente a la libre prestación de servicios. Se trataba de que dicha prestación fuera, durante el período transitorio, progresivamente liberalizada en todos los países de la Comunidad, a partir de un Programa General de supresión de restricciones establecido por el Consejo, por unanimidad, a propuesta de la Comisión y previa consulta al Comité Económico y Social y al Parlamento Europeo (arts. 59 y 63). Entre estos servicios, tipificados en el artículo 60 del Tratado, se encontraban las "actividades propias de las profesiones liberales». Sin embargo, aquellas profesiones (como la abogacia) que «estén 
relacionadas, aunque sólo sea de manera ocasional con el ejercicio de poder público» no quedan bajo la cobertura de la libertad de establecimiento (art. 55 del Tratado). No obstante, por lo que respecta a la profesión de abogado, el Tribunal de Justicia ha corregido la interpretación literal del Tratado en su sentencia de 21 de junio de 1974 al considerar que se trata de una actividad liberal que no comporta uuna participación directa y específica en el ejercicio de la autoridad pública».

El mismo Tribunal de Justicia, en sentencia de 15 de julio de 1964, había definido por restricción "toda medida que tiene por objeto someter el establecimiento de los nacionales de los otros Estados miembros a una reglamentación más severa que la reservada a los nacionales y esto cualquiera que sea el régimen jurídico» de la actividad desplegada.

Siguiendo a Fernández de la Gándara y Calvo Caravaca (46), para combatir las restricciones a la libertad de establecimiento, la Comunidad ha abierto, con desigual fortuna, cuatro vías. La primera, tratar de eliminar toda discriminación por razón de la nacionalidad (que serviría para que los títulos de un Estado fueran efectivos para todo el que los obtuviera, al margen de su nacionalidad). La segunda vía estribaría en la elaboración y aprobación de directivas encaminadas a facilitar el reconocimiento mutuo de diplomas, certificados y otros títulos, de acuerdo con el artículo 57.1 del Tratado. En tercer lugar, se propuso la coordinación, también mediante directivas, de las legislaciones de los Estados miembros sobre ejercicio y régimen de las profesiones liberales. Por último, se viene ensayando una "solución pragmática» consistente en permitir el establecimiento de personas que ya han ejercido en su país la misma actividad, siempre que justifiquen ante el Estado de acogida un certificado acreditativo de su experiencia profesional. El Tribunal de Justicia de las Comunidades ha venido removiendo obstáculos a la libertad de establecimiento y ejercicio profesional en sentencias bien conocidas como las de 3 de diciembre de 1974, 27 de abril de 1977, 31 de enero de 1984 y 12 de julio del mismo año.

Entre las Directivas más significativas cabe destacar la $77 / 249$, de 22 de marzo de 1977, mediante la que el Consejo trató de facilitar el ejercicio efectivo de la libre prestación de servicios por los abogados; las Directivas 1026 y 1027, de 18 de diciembre de 1978, sobre los profesionales de la veterinaria (la primera sobre reciprocidad de diplomas, títulos y libre establecimiento y la

(46) Fernández de la gándara, L., y Calvo Caravaca, A. L.: Libertad de establecimiento $y$ derecho de sociedades en la Comunidad Económica Europea, Tecnos, Madrid, 1988. pp. 41 y ss. 
segunda sobre coordinación de disposiciones legales sobre esta profesión, incluidos los años y materias básicas de la carrera); la Directiva 75/362, de 16 de junio de 1975, sobre reconocimiento y homologación de títulos y derecho de establecimiento de los profesionales y especialistas de la medicina o la más antigua Directiva 64/224, de 25 de febrero de 1964, sobre libre establecimiento $y$ actividad profesional de intermediarios, comerciantes, industriales y artesanos. Todas estas disposiciones se dictaron a partir del Programa General antes aludido, previsto en el artículo 63 del Tratado de Roma y aprobado en 18 de diciembre de 1961.

\section{B) LA TITULACIÓN PARA EJERCER}

La Constitución española de 1869 ya se refería (art. 25) a los "títulos de aptitud» necesarios para acceder a determinadas profesiones. La vigente Ley Fundamental habla en su artículo 35.1 de «profesión u oficio», sin duda queriendo referirse a una distinción por razón del tipo de preparación y tal vez apuntando a uno de los significados de la palabra oficio, consistente en «trabajo mecánico o manual». La noción de profesión, su régimen y eventual sistema de colegiación debe ser creación legislativa (como se deduce de la sentencia constitucional $81 / 1985$ ).

Pero no puede identificarse necesariamente la profesión con un determinado tipo de títulos académicos, aunque la misma Constitución se preocupa de colocar una conjunción copulativa entre títulos académicos y profesionales (art. 149.1.30. ${ }^{\circ}$. Para ejercer una actividad podemos encontrarnos con muy diversa casuística que, aún no exhaustivamente, podemos resumir así:

- Títulos académicos que conducen directamente a una profesión, incluso sin necesidad de colegiación (este ha venido siendo el régimen de los economistas) (47);

- Títulos académicos que requieren de la colegiación para poder ejercer una o varias profesiones (el título de Licenciado en Derecho para ser abogado o procurador);

- Títulos que capacitan para acceder a pruebas de ingreso para ejercer una profesión colegiada. Aquí cabría decir que el título académico es requisito previo al título profesional y éste, a su

(47) Tradicionalmente la profesión de economista ha venido ejerciéndose en empresas, o a través de asesorías y consultings, por lo que la colegiación no era requisito forzoso, como señalan MARTNN MATEO, R., y SOSA WAGNER. F., en Derecho Administrativo Económico, Pirámide, Madrid, 1977, p. 128 y s. Aunque el Real Decreto $871 / 1977$, de 24 de abril, ha querido profundizar en la necesidad de colegiación para los economistas, se ha quedado en una forma híbrida, ya que su artículo $1^{\circ}$ se limita a establecer que «sólo podrán utilizar la denominación profesional (de Economistas) los titulados... que se hallen incorporados a los Colegios de Economistas correspondientes». 
vez, es indispensable para darse de alta en un Colegio Profesional. Al margen de profesiones bien conocidas a las que se accede mediante oposición (48) controlada por la Administración (aunque los profesionales no sean funcionarios), conviene citar algún ejemplo significativo en el que el título profesional uniforma títulos académicos heterogéneos. Tal es el caso de los agentes de la propiedad inmobiliaria, cuyo título profesional único se obtiene tras una prueba a la que pueden concurrir titulados superiores de cualquier carrera y diplomados de primer ciclo en Derecho, Economía, Arquitectura e Ingeniería Técnica y Profesorado Mercantil (art. 5 del Real Decreto 1613/1981, de 19 de junio). No existe aquí una coordinación entre los títulos académicos a que se refiere la Ley Orgánica de Reforma Universitaria (art. 30) y los títulos profesionales pese a que el artículo $149.1 .30^{\mathrm{a}}$ de la Constitución los une a la hora de atribuir al Estado la competencia reguladora y de homologación. Caso similar al citado es el de los administradores de fincas y no menos significativo el de los gestores administrativos. En el caso de estos últimos, desde el Decreto de 1 de marzo de 1963, se exige titulación superior (Derecho, Económicas, Empresariales o Políticas) para presentarse a las pruebas de aptitud. Como, agudamente, se ha hecho notar (49) «para un licenciado en Derecho es, pues, más difícil ser gestor administrativo que ejercer de abogado (para lo que le basta con el título, sin prueba), siendo así que según el artículo $1 .^{\circ}$ (del Estatuto de los Gestores) éstos se dedican... "a promover, solicitar y realizar toda clase de trámites que no requieran la aplicación de la técnica jurídica reservada a la abogacía".".

- También existen títulos profesionales -previos a la necesaria colegiación- que no requieren de título académico para la superación de las pruebas de aptitud. Es el caso de los agentes y corredores de seguros (art. 5 del Real Decretolegislativo de 1 de agosto de 1985) que sólo precisan de una prueba para obtener la habilitación profesional, especificándose en la normativa orgánica, que tal medida selectiva no es aplicable a quienes posean títulos académicos que supongan conocimientos al efecto.

Las disfunciones citadas debieran ser revisadas a la luz de lo dispuesto en la Constitución, tanto por la competencia homologa-

(48) Véase la última convocatoria de oposiciones para la ciobtención del título de Notario» (Resolución de la Dirección General de Registros y del Notariado de 8 de noviembre de 1988).

(49) LÓPEZ RAMÓN: «Reflexiones...», cit. pp. 672 y s. 
dora del Estado como desde el principio de libertad, claramente obstaculizado por un buen número de normas, a veces de rango menor, que rozan el absurdo. A los Poderes públicos compete remover los obstáculos que dificulten el ejercicio de las libertades y entre éstos, sin duda, se hallan las múltiples trabas gremiales y corporativas a la libertad profesional. Impedimentos que no deben tener otro sentido que la garantía de los derechos de terceros (especialmente frente a impericias profesionales), la ordenación de los estudios universitarios y cualquier otro valor constitucional que pudiera imponerse a la libertad de ejercicio profesional.

Tal vez se imponga una reacción contra el gremialismo excluyente como la que se produjo con la promulgación de la Constitución de Cádiz. Como es sabido, esta norma intentó acabar con los privilegios corporativos que anegaban la libertad industrial y de oficio (50). En su virtud, las Cortes Generales y Extraordinarias expidieron un Decreto el 8 de junio de 1813 sobre "Libertad en el establecimiento de fábricas y oficios». Esta norma; tan de actualidad, enlaza la libertad de empresa con la de elección y ejercicio de oficio, tal como bien recientemente ha hecho el Tribunal Constitucional: Su tenor literal es el siguiente:

«1. ${ }^{\circ}$ Todos los españoles y extranjeros avecindados o que se avecinden en los pueblos de la Monarquía, podrán libremente establecer las máquinas o artefactos de cualquier clase que les acomode sin necesidad de permiso ni licencia alguna, con tal que se ajusten a las reglas de policía adoptadas o que se adopten para la salubridad de los mismos pueblos.

2..$^{\circ}$ También podrán ejercer libremente cualquiera industria u oficio útil, sin necesidad de examen, título o

(50) La Constitución de Cádiz abolió la concesión de privilegios, tanto personales como corporativos (art. 172.9. ${ }^{2}$ ) y trató de "remover los obstáculos» que impedían el establecimiento libre de los industriales de toda especie (art. $131.211^{\text {a) }}$. El Diccionario de la Administración Española, de ALCUBILLA (Vol. II, 6. ${ }^{\text {a }}$ ed., Madrid, 1914, p. 74) nos ilustra sobre las trabas impuestas a la libertad industrial y de oficio por el poder de los gremios, mediante aprendizajes forzosos, limitación de plazas de oficiales industriales y otros privilegios con los que intentó acabar la Constitución de 1812. Por otra parte, la dignidad de los oficios o artes mecánicas «que no exigen título para su ejercicion, es valoración relativamente moderna. Una Real Cédula de 18 de marzo de 1783 (a seis años sólo de la Revolución Francesa) declararía uhonestos y honrados» los oficios de curtidor, herrero, sastre, zapatero, carpintero "y otros». También es de sumo interés la explicación sobre los gremios que da Joaquín ESCRICHE en su Diccionario razonado de Legislación y Jurisprudencia, Maillefert y Cla., París, 1863, pp. 1.351 y s., voz noficion. La doctrina penal, recordando a A. Groizard y al Código Penal de 1870 aún cita una sentencia del Tribunal Supremo de 22 de enero de 1894 por la que se absolvía del delito de usurpación de funciones (entonces en el artículo $343 \mathrm{CP}$ ) a un presunto intruso que ejercía y se anunciaba públicamente como «profesor en castraciónn. La absolución se produce por no tratarse de una profesión, sino de «un simple oficion, según el Reglamento de 14 de octubre de 1853, que sólo prescribía la necesaria licencia del Director de la Escuela de Veterinaria. La omisión de tal autorización es considerada por el Tribunal como una simple falta. 
incorporación a los gremios respectivos, cuyas ordenanzas se derogan en esta parte.»

Esta idea aún se mantendrá, como hemos visto, en los textos constitucionales progresistas de 1869 y 1873, donde sólo las profesiones tituladas quedaban a merced de la correspondiente aptitud declarada por el Estado. La misma Constitución de 1876, en aparente contradicción, habla primero de la libertad de elegir. profesión de cada cual, incluyendo el derecho «a aprenderla como mejor le parezca" y posteriormente, se refiere a las competencias del Estado para expedir y controlar los títulos profesionales habilitantes (art. 12). Pero no existe incongruencia alguna: el principio de libertad total, por la que se permite ser autodidacta, rige para los oficios y profesiones no tituladas, en tanto que existe una restricción para otras dedicaciones laborales para las que el Estado (no los gremios) considere imprescindibles unos estudios reglados. Bien elocuente es, en este sentido, la identidad que se establece en el Diccionario Alcubilla entre oficios y artes mecánicas "que no exigen título para su ejercicio».

Hoy en día, junto a un exacerbado corporativismo que tiende a subyugar la libertad de oficio o profesión bajo la excusa de una dignificación colegial y reivindicativa de cada actividad (cuya falsedad intuyeron lúcidamente los Padres de la Patria gaditanos), aún nos encontramos con pugnas entre profesiones afines por la colisión de atribuciones.

Entre estas colisiones corporativas por la exclusividad de funciones cabe recordar las tradicionales de los Cuerpos de ingenieros (51) entre sí y con respecto a los arquitectos $y$, más recientemente, las luchas entre títulos medios y superiores; la concurrencia de varios títulos académicos (químicos, farmacéuticos, médicos...) para acceder a la profesión de analista, la reivindicación de los estudios del suelo por geólogos e ingenieros de minas y así hasta llegar a una interminable lista de ejemplos de cotidiana actualidad.

En este sentido es esperanzadora la reciente jurisprudencia del Tribunal Supremo, que aún sin invocar el artículo 35.1 de la Constitución (norma, por cierto, de directa aplicación) tiende a fijarse más en la «capacidad técnica real» de cada tipo de titulación que en los monopolios tradicionales de cada profesión.

(51) Cifr. Garcia de EnTERria, E.: La Administración Española, 2. a ed., Madrid, 1964, en el capitulo "La Administración y sus agentes: revisión de estructuras», trabajo cuyas directrices siguen MUÑOZ MACHADO PAREJO y RUILOBA en op. cit., pp. 40 y ss. 
Así la sentencia de 7 de octubre de 1986 señala que

"La competencia de cada rama de la Ingeniería depende de la capacidad técnica real para el desempeño de las funciones propias de la misma (sentencias de 26 de febrero de 1966, 16 de marzo de 1967, 31 de diciembre de 1973 y 24 de marzo de 1975) ya que el ejercicio profesional libre es hoy una realidad social fácilmente constatable con apoyo en los artículos 4 y concordantes de la Ley de Reordenación de las Enseñanzas Técnicas de 20 de julio de 1967 y que implícitamente estaba consagrado ya por el artículo 14 del Reglamento de 20 de septiembre de $1926 \ldots$ (52).

Por su parte, la sentencia de 21 de octubre de 1987 ratificará estas mismas conclusiones al manifestar que

«No puede admitirse un monopolio de proyección de cada tipo de construcciones (con excepción de la vivienda humana) a favor de profesión determinada, ya que, al contrario, tal competencia en exclusiva no aparece atribuida específicamente a nadie, a la vez que las diferentes reglamentaciones ofrecen perspectivas de competencias concurrentes sin reglas precisas de delimitación. La doctrina de esta Sala en sus últimos años ha rechazado el monopolio competencial... (dando) entrada a todo título facultativo oficial que ampare un nivel (similar e idóneo) de conocimientos" (53).

Sería conveniente ahondar en esta vía, desde el respaldo de la interpretación pro libertate, para lo cual sería conveniente algún

(52) Sentencia de 7 de octubre de 1986. Sala 4. ${ }^{a}$. Ponente señor González Navarro. Referencia del repertorio Aranzadi núm. 2.626. Esta sentencia es confirmatoria de la a quo dictada por la Audiencia Territorial de Zaragoza. Sobre la ruptura de la correspondencia entre las Enseñanzas Técnicas y los Cuerpos funcionariales (iniciada por las Leyes de $\mathbf{2 0}$ de diciembre de 1952 y 20 de julio de 1957), vid. MUÑOZ MACHADO PAREJO y RUILOBA: La libertad de ejercicio..., cit. pp. 44 y ss.

(53) 'Sentencia de 21 de octubre de 1987, Sala 4.a-Ponente señor Garcia-Ramos Iturralde, R. Aranzadi, núm. 8.685. Véase, en sentido un tanto contrario, la sentencia de la misma Sala de 24 de julio de 1987, R. Aranzadi, 7.676, sobre la procedencia de excluir en una convocatoria de una plaza de inspector químico-farmacéutico a una rama concreta de la Ingeniería; no obstante, a nuestro juicio, es razonable tal exclusión por el tipo de conocimientos exigidos en la prueba. Más significativa es la sentencia, también de la Sala $4 .^{\mathrm{a}}$ del Tribunal Supremo, de 17 de marzo de 1986 (R. Aranzadi, núm. 1.831) por la que se desestima el recurso del Colegio de Arquitectos de Valencia que había impugnado la realización de un "avance de plan urbanístico». realizado por un conocido profesional («R.B.») sin título español. El Tribunal Supremo, igual que había hecho la Audiencia, no penetrará en el espinoso tema del artículo 35.1 de la Constitución y se acogerá a que los avances de ordenación tienen una ulimitada finalidad... sin alcance vinculante» por lo que no requieren las condiciones técnicas exigidas a los Planes por el artículo 31.2 de la Ley del Suelo. 
apoyo legislativo. Cierto es, que el Tribunal Constitucional no ha querido saber nada de hipotéticos «contenidos esenciales garantizados» de cada profesión. Pero, por esa misma razón, parece conveniente reforzar la libertad de elección profesional, eliminando el mayor número de cortapisas competenciales introducidas en normas de organización o corporativas que nos han devuelto en el tiempo a los umbrales del constitucionalismo español.

Ese giro legislativo, entendemos que también debería afectar, dentro de la obligada referencia constitucional, a los Colegios Profesionales, sobre cuyos problemas jurídicos no vamos a insistir en este trabajo, remitiéndonos al trabajo específico que se recoge en esta obra colectiva (54).

\section{Libertad profesional y derechos laborales}

La incardinación conjunta de la libertad de elección profesional y del derecho al trabajo en el artículo 35.1 de la Constitución, nos obliga a realizar un breve comentario al respecto. Ciertamente, esta relación expresa es novedosa en el constitucionalismo español y su precedente más inmediato debe buscarse en el artículo 5.1.1 de la Constitución portuguesa de 1976 (55). Entre los textos internacionales debemos recordar el artículo 23 de la Declaración Universal de Derechos de las Naciones Unidas donde también aparecen conectados ambos derechos. El derecho al trabajo se ofrece indisolublemente unido en los textos constitucionales al deber de trabajar. En ese sentido, el artículo 35.1 de la Constitución española es respetuoso con la rúbrica "derechos y deberes» de la Sección segunda, capítulo II del título I. Sin embargo, teniendo en cuenta que los preceptos de la meritada sección son de inmediata aplicación, más parece que el reconocer a «todos los españoles» el derecho al trabajo se aproxima más a un principio rector socioeconómico que a un derecho que vincula a los Poderes públicos. Y ello por mucho que se matice tal derecho como una simple posibilidad igualitaria de acceder al empleo. El cotejo con otros artículos de la misma sección es claramente elocuente de la poca afortunada inclusión - un tanto demagógica e ingenua- del derecho al trabajo entre los derechos inmediatamenté efectivos. La diferencia doctrinal entre derecho al trabajo y derecho a un puesto de trabajo aún

(54) Encomendado al profesor J. L. VILLAR P.t6ALASI. Sobre la existencia de otras al ejercicio profesional (determinadas licencias de actividades clasificadas, licencia fiscal, etcétera), vid. SAINZ MORENO: "Comentario al artículo 36 ...", cit., pp. 525 y ss.

(55) También en el artículo 4 de la Constitución mejicana $y$ en el 12.1 de la Ley Fundamental de Bonn pueden encontrarse referencias similares. El artículo XIII (de Enmienda) de la Constitución de los Estados Unidos sólo se refiere a la obligación del trabajo forzado, salvo a título de condena. 
siendo teóricamente impecable, no deja de ser un síntoma de frustración para un Estado que se declara social.

El correlativo deber de trabajar también contiene una gran dosis de abstracción. Máxime si entendemos que las prestaciones personales obligatorias son cuestión distinta de tal deber(56). Pero, aún partiendo de una hipotética situación de pleno empleo donde pudiera exigirse a todos la carga del trabajo, ¿incluiría ésta el necesario conocimiento de una profesión u oficio? Nos parece que la respuesta debe ser negativa. Primero, porque aún existen multitud de actividades diversas, de libre desenvolvimiento, que no se hallan reguladas como profesiones u oficios corporativos. En segundo lugar, porque la elección de profesión u oficio es libre no sólo en el contenido sino también en la decisión; es decir: la Constitución no habla de la obligación de todos de elegir voluntariamente una ocupación. En tercer lugar, porque es factible la existencia de ocupaciones no sometidas al derecho del trabajo; baste para ello pensar en la vieja expresión "sus labores» que se vino aplicando al trabajo doméstico de la mujer $y$, por último, porque la obligación de poseer un oficio definitivo obstaculizaría el derecho al cambio de trabajo como medio de promoción personal tutelado por el ordenamiento.

Esa promoción a través del trabajo (que aparece en el artículo 35. 1 de la Constitución por delante del derecho a la justa remuneración y a la no discriminación laboral por razón de sexo) figura recogida en el artículo 7 c) del Pacto Internacional de Derechos económicos, sociales y culturales, de 19 de diciembre de 1966 (57), así como en los artículos 22, 24 y 25 del Estatuto de los Trabajadores aprobado por Ley de 10 de mayo de 1980 (58). La promoción a través del trabajo debe incluir el cambio de éste, ya que el derecho que se reconoce es a la mejora "a través» de la actividad laboral y no mediante un mismo trabajo. La única

(56) Cfr. STEIN E.: Derecho político, cit. p: 175. El trabajo sería el medio de ganarse la vida, en tanto que las prestaciones obligatorias derivan de la exigencia de la colaboración ciudadana como consecuencia de la subordinación de los intereses individuales a los generales del Estado. Sin embargo, para el sujeto que ha de padecer una actividad forzosa, tal vez sea indifirente la diversa naturaleza jurídica de la institución por la que se le obliga a trabajar contra su voluntad. La diferencia entre trabajo forzado y prestación personal obligatoria es, a nuestro juicio, excesivamente teórica, ya que el criterio de la remuneración del trabajo también es falaz pues. la milicia preceptiva $u$ otras prestaciones subjetivas también pueden estar gratificadas en metálico o mediante manutención.

(57) Ratificado por el Reino de España el 13 de abril de 1977. El artículo 7. cl, mencionado en el texto dispone la garantía de una uigual oportunidad para todos de ser promovidos dentro de su trabajo, a la categoria superior que le corresponda sin más consideraciones que los factores de tiempo, servicio y capacidad". Aunque el. Pacto hable de promoción "dentro de su trabajon es evidente que el pleno desarrollo de la persona no puede estancarse en una misma empresa.

(58) Vid., SAgARdoY Bengoechea J. A.: "Comentario al articulo 35...», cit. pp. 469 y ss. 
vinculación, lógicamente, procede de las estipulaciones del contrato en cuanto a su duración. Pero es obvio que confinar a una persona al desempeño perpetuo de una actividad es una forma de esclavitud.

Por otra parte, cuando el trabajo es la concreción asalariada del ejercicio de un oficio o profesión, es evidente que la elevación de categoría laboral o el mismo cambio de actividad son manifestaciones dinámicas del derecho a la libertad profesional.

\section{Oficios y profesiones ante la protección penal}

Una de las tradicionales reivindicaciones gremiales ha consistido en la tutela criminal frente al intruso. Protección que más debiera guardar relación con los derechos de terceros, amenazados ante la impericia profesional (59), que con la defensa de las corporaciones que, a lo sumo, debiera atenderse por vía civil o administrativa.

Pero el Código Penal ha atendido, singularmente desde la reforma de 1963, las peticiones tuitivas de los profesionales reglamentados. Hasta el citado año sólo se consideraba delito la usupación de funciones o atribución pública de la cualidad de profesional. Desde 1963 también se incluyen en el artículo 321 , como delito, actos de ejercicio de profesión titulada oficial que, hasta esa fecha eran meras faltas y que, desde entonces, pasan a estar penados con prisión menor. Actualmente se tipifican como faltas (artículo $572 \mathrm{CP}$ ) el ejercicio de actos propios de profesiones reglamentadas (no tituladas) sin poseer la habilitación o capacitación oficial requerida y el ejercicio de profesión por titulado o habilitado no colegiado cuando la inscripción corporativa sea obligatoria (60).

No obstante, el Tribunal Supremo ha enfocado, en ocasiones con sumo acierto, la cuestión del bien jurídico protegido al afirmar, por ejemplo en la sentencia de 1 de diciembre de 1970, que el propósito del legislador al redactar el artículo 321 del código punitivo,

«... no fue tanto impedir la ilícita competencia que a los profesionales verdaderos pudieran hacer los profanos, con el consiguiente perjuicio económico, como prevenir el peligro que pudieran crear personas imperitas 0 indoctas con actividades intrusas...».

(59) La impericia o negligencia grave del profesional también es un delito tipificado en el artículo 565. párrafo 5. ${ }^{\circ}$, del Código Penal.

(60) Cfr. LUzon PẼ̃̃a, D., en Anuario de Derecho Penal y Ciencias Penales, núm. 38, Madrid, s.v.: MANZanaRes SAMANiego y AlbaCAR LÓPEz: Código Penal (comentarios $y$ jurisprudencia, Comares, Granada, 1987, pp. 696 y sS.; SAINZ MORENO: "Comentario al artículo 36...», cit. p. 527. 
En parecidos términos se expresará la sentencia de 26 de marzo de 1977 al considerar prioritaria la protección de la sociedad ante el peligro de los intrusos en materias delicadas o de gran trascendencia. Pero por esta misma razón aducida jurisprudencialmente, creemos que la equiparación de todo tipo de intrusismo a través de la carencia de título oficial es injusta. Al no hablarse de título académico o profesional, ambos están comprendidos en la expresión «título oficial» del artículo 321 del Código Penal. Y con todos los respetos, no es lo mismo el «daño social» causado por un falso arquitecto o médico que por un administrador de fincas o un agente inmobiliario. La impericia de éstos ya tiene otras contemplaciones punitivas y civiles, por lo que la protección corporativa no es razonable y menos si se niega (como hace el Tribunal Supremo) que esta tutela vaya por delante de la defensa social ante prestaciones temerarias (61). Una vez más creemos imprescindible una actuación normativa estatal que, a la vez que restablezca en sus justos extremos la libertad profesional, esclarezca las oscuras y disparatadas relaciones entre título académico y profesional.

Pero las profesiones y oficios tienen más conexiones con el Derecho penal (prescindiendo ahora de la profesión funcionarial). Desde antiguo, los autores vienen reclamando una protección específica del secreto profesional como derecho inherente al ejercicio de actividades liberales. Sobre este punto no debemos ocultar la discriminación constitucional establecida en el artículo 20.1.d) del texto fundamental, al reconocer, con toda suerte de amparos, bajo el pretexto de la libertad de expresión, el secreto profesional de los trabajadores de la información, en tanto que otras actividades donde la confidencialidad tiene mayor importancia quedan desprotegidas (62).

El Código Penal también contempla la profesión u oficio al referirse a las penas; entre las de carácter grave se encuentran la inhabilitación especial y la suspensión de profesión u oficio (arts. $27,30,41,42 \ldots$ del $C P$ ), que pueden tener carácter principal o

(61) También existen casos claros de intrusismo que sí deben recriminarse en buena lógica, en los supuestos en que una Ley encomienda expresamente una labor a un determinado profesional (las leyes de Enjuiciamiento a los abogados y procuradores, la Ley del Suelo a los arquitectos, etc.). Entre las sentencias del Tribunal Supremo por usurpación de funciones, cabe citar las referidas a las siguientes profesiones: médicos (1 de diciembre de 1970 y 23 de enero de 1984), odontólogos (26 de febrero de 1981), 6pticos (5 de mayo de 1982), farmacéuticos (14 de febrero de 1983), abogados (28 de septiembre de 1982), arquitectos (27 de septiembre de 1984) y agentes de la propiedad inmobiliaria (23 de febrero de 1983). Estas y otras decisiones judiciales pueden consultarse, sistematizadas, en MANZANARES SAMANIEGO y ALBACAR LÓPEZ op. loc. cit.

(62) La Ley General de Sanidad, de 25 de abril de 1986, contempla, en su artículo 10, el derecho recíproco al secreto profesional: la confidencialidad del expediente de cada usuario del servicio público de la salud. 
accesorio. Cuando tengan carácter accesorio la privación del ejercicio de profesión u oficio sólo podrá imponerse si dicha actividad hubiera tenido relación directa con el delito, debiendo especificarse en la sentencia, tal previsión es elogiable a la luz de la Constitución vigente, ya que si la elección profesional y el derecho al trabajo son derechos constitucionales sólo regulables por ley, y ésta ha de respetar en todo caso su contenido esencial, parece claro que la limitación de dichos derechos sólo debe hacerse en relación con el delito que se pena y no como un plus sancionador.

\section{PROFESION PUBLICA Y PROFESION PRIVADA}

Se ha señalado, en estudios del máximo interés (63), que muchas de las actuales profesiones tituladas de ejercicio liberal provienen de los Cuerpos de funcionarios que, desde el último tercio del siglo XVIII y, básicamente, durante el pasado siglo, fue creando la Administración para hacer frente a las nuevas tareas a las que va sirviendo. Tal fue el caso de los ingenieros de minas (creados por Real Orden de 14 de enero de 1777), de caminos, canales y puertos (Real Orden de 12 de junio de 1799) o navales (Real Orden de 7 de junio de 1848, con precedente en 1770). Creado el Cuerpo, se creaba la Escuela (por ejemplo, Real Orden de 27 de julio de 1803), que no sólo otorgaba habilitaciones académicas, sino que propiamente creaba la carrera funcionarial, a la que se accedía sin solución de continuidad desde los estudios. No fue de extrañar que las competencias administrativas sobre las tareas desempeñadas por estos Cuerpos acabaran siendo reclamadas por los funcionarios como propias y excluyentes de su profesión. De aqui derivará el conocido celo competencial de determinadas profesiones, ya liberalizadas.

Pero en nuestros días aún encontramos ejemplos de identidad entre profesión y función pública en las tres carreras militares. El militar sale de la Academia convertido en un servidor público, que a la vez que se ha ido formando en la sujeción administrativa del estudio se ha sometido también a la sujeción funcionarial.

Por otra parte, existen profesiones que se ejercen tanto para la Administración como en el libre mercado. Abogados, ingenieros, médicos o arquitectos prestan sus servicios, previa selección, a las Administraciones públicas de la misma forma que podían haberlo hecho $-y$ aún existen compatibilidades sangrantes al respecto-

(63) Citados en nota núm. 51. 
para el sector privado. Inversamente, hay actividades profesionales que el Estado no desarrolla tradicionalmente y otras que, por su componente de autoridad o singularidad, no tienen parangón en el mundo privado (caso de la carrera judicial, fiscal o diplomática). El caso del profesorado admite algunos matices, ya que la enseñanza pública o privada no siempre conduce a los mismos fines, aunque la regla general sea la homologación de las enseñanzas privadas y sea frecuente el paso del profesorado de un tipo de enseñanza a otra, acreditando así la unidad de la profesión.

En fin, parece obvio que la función pública, como elección personal de cada ciudadano, es una forma de actividad profesional como otra cualquiera. Ocurre, sin embargo, que el artículo 23.2 de la Constitución, como es bien notorio, confiere al acceso igualitario a la función pública la condición de derecho fundamental, sin duda por la mayor necesidad de garantía de los ciudadanos ante la oferta de empleo de los poderes públicos y por la trascendencia de la relación funcionarial. $Y$ también, por la común ubicación del derecho a acceder a cargos públicos, que parece requerir la máxima tutela constitucional, no parece injustificado el distinto encuadre sistemático y tuitivo del ingreso en las funciones públicas con respecto a las privadas.

El acceso a los empleos y cargos públicos, con arreglo a los principios de capacidad, mérito e igualdad, es uno de los derechos decanos del constitucionalismo español. Tal vez la primera vez que se utiliza esta expresión tiene lugar en el Proyecto de Istúriz de 28 de julio de 1836 (art. $2 . \%$, de donde pasará sucesivamente a las Constituciones de 1837 (art. 5), 1845 (art. 5), no promulgada de 1856 (art. 6), 1869 (art. 27), proyecto de 1873 (art. 29), 1876 (art. 15), proyecto de 1929 (art. 27) y 1931 (art. 40, donde se hace una referencia a la igualdad por razón de sexo). La expresión «empleos y cargos públicos" será variada por la de "cargos y funciones públicas» por las Leyes Fundamentales (VIII Principio Fundamental del Movimiento y art. 11 del Fuero de los Españoles). Esta expresión, "funciones públicas», también se utilizará en la Declaración Universal de Derechos Humanos (1948), en su artículo 21.2. así como, entre otras, en la Constitución portuguesa (art. 48.4). La vigente Constitución española habla, en esta última línea, de "funciones y cargos públicos», pero ha escindido, contra toda una tradición de siglo y medio, la referencia al acceso conforme a los principios de capacidad y mérito que ahora se recogen separadamente (fuera de los derechos fundamentales y de la regulación por ley orgánica) en el artículo 103.3 de la Ley Fundamental. El núcleo, pues, de la protección fundamental del acceso a la función pública lo constituyen las "condiciones de igualdad». No deja de ser 
también curioso que después de haberse cambiado el término «empleos públicos» por el de "funciones públicas» comience a emerger con más fuerza en la legislación funcionarial la expresión «empleo público» para referirse tanto a los funcionarios como al personal laboral al servicio de la Administración (por ejemplo, en el capítulo III de la Ley 30/1984, de 2 de agosto).

Como acabamos de ver, la regulación del acceso a funciones públicas, por su connotación de ejercicio de poder (como dirá la Constitución de 1869), ha estado siempre separada de la libertad de elegir otras profesiones privadas, pese a los orígenes funcionariales de buena parte de las profesiones liberales hoy existentes. Pero la libertad de opción también abarca la disyuntiva entre empleo privado y ocupación pública. Por otro lado, en los tiempos actuales es frecuente asistir tanto a intentos de rescatar para el sector público profesiones extrañamente privadas como a desregulaciones (64) de cometidos públicos que se tornan privados. Mientras que en el segundo de los casos el ordenamiento dispone de medios para atemperar lo que puede ser un menoscabo de la profesión elegida (como ha ocurrido recientemente con los agentes de Cambio y Bolsa) (65), en el supuesto de la transformación en públicos de empleos privados podrían aparecer problemas de tenor económico de no fácil resolución. Ciertamente, no se aprecia claramente un derecho futuro de los que obtienen, por ejemplo, el título de notario (66) a terminar sus días en activo como profesionales privados que dan fe pública. Pero no olvidemos que el Tribunal Constitucional ha declarado que la mera "frustración de las expectativas existentes» puede producir, «en determinados casos, perjuicios económicos que pueden merecer algún género de compensaciónı (67). Ante la complejidad de evaluación de esos perjuicios, parecería conveniente, siempre que se deseara rescatar una profesión privada, la utilización de un régimen transitorio para

(64) Cfr. MARTIN MATEO R.: Liberalización de la Economía. Más Estado, menos Administración, Trivium, Madrid, 1988, pp. 154 y ss.

(65) Véase la Disposición Transitoria $3 .^{a}$ de la Ley 24/1988, de 28 de julio, sobre Mercado de Valores, asi como las Directivas comunitarias 73/183, de 28 de junio de 1973; 77/780, de 12 de diciembre de 1977, y 83/350, de 13 de junio de 1983, de las que trae causa la reordenación del Mercado de valores y sus intermediarios.

(66) Sobre el carácter no funcionarial de las Notarías y sus empleados, pueden verse las sentencias del Tribunal Supremo de 4 de abril de 1979, 18 de abril de 1984 y 29 de julio de 1987 (todas de la Sala 5. ${ }^{\mathrm{a}}$ ). Sobre la producción de actos de contenido administrativo por las Mutualidades de empleados de notarías y por la Dirección General, véase, incidentalmente, el auto de la Sala 4. ${ }^{a}$ del Tribunal Supremo de 17 de marzo de 1987.

(67) Sentencia constitucional 99/1987, de 11 de junio, relativa al enjuiciamiento de la Ley de Medidas de Reforma de la Función Pública. Otras argumentaciones sobre la diferencia entre derechos adquiridos e irretroactividad del ordenamiento pueden encontrarse en las sentencias constitucionales $42 / 1986$, de 10 de abril (Fundamento jurídico $4 .^{\circ}$ ) y $108 / 1986$, de 29 de julio (Fundamento jurídico $17 . \%$. 
quienes se ven afectados por la medida después de haber obtenido el título profesional, que, de esta forma, quedarian "ra extinguir». Pero una vez más se nos hace patente la artificiosidad de la separación entre trabajo público y privado: el patrón puede cambiar, pero la profesión se mantiene.

\section{REFLEXION FINAL}

La libertad de elegir profesión u oficio, como hemos visto, no puede ser estudiada desde una solitaria y aséptica exégesis del artículo 35.1 de la Constitución. Este derecho, cuyo arraigo constitucional en España no tiene parangón en ordenamientos comparados, requiere ser interpretado desde una visión conjunta de la Constitución, de sectores extraadministrativos del ordenamiento y de la realidad social con la que se encuentra la norma fundamental en el momento de su promulgación.

Pero la propia Constitución impide una clara y rápida armonización de las múltiples oscuridades presentes en un tejido social corporativo y gremialista, amparado por una telaraña reglamentaria, ya que la misma Ley Fundamental, a la vez que proclama el principio de libertad, ensalza el régimen de Colegios Profesionales.

La libertad de elección de profesión u oficio posee un contenido esencial centrado en la opción voluntaria de la actividad. Nuestro Tribunal Constitucional no considera que la «imagen profesional» (tan familiar de la doctrina alemana) de cada actividad esté ínsita dentro de esa elección, ya que cada profesión u oficio no tiene un contenido esencial constitucionalmente garantizado. Sin embargo, el principio de libertad sí nos ofrece pautas sobre la inconveniencia de regular (y restringir) el acceso a cada oficio y profesión y, de otra parte, el principio de legalidad nos exhorta a plantearnos la inconveniencia de las reglamentaciones corporativistas prácticamente independientes de normas con rango de Ley.

La relación entre títulos académicos y profesionales no debiera ser cuestión de baladi, para evitar protecciones absurdamente igualitarias de situaciones completamente diferentes. Protecciones que llegan, incluso, con los rigores propios de la justicia criminal.

El bien jurídico a proteger es, fundamentalmente, la seguridad de los usuarios ante las impericias de profanos en los distintos cometidos laborales. También se puede hablar de las competencias estatales $-y$ autonómicas- para organizar el sector profesional. Campo éste cada vez más proclive a la desaparición de fronteras y restricciones en el establecimiento. El Estado puede $y$ debe relacionar su atribución homologadora de títulos académicos con la 
razonable existencia de títulos profesionales, tal y como invita el artículo 149.1.30 ${ }^{\circ}$ de la Constitución.

Por último, los Poderes públicos deben proteger otras premisas y valores protegidos constitucionalmente, como es el caso de la disciplina de mercado. Y fuera de estas lógicas actuaciones públicas, al Estado sólo le queda remover los obstáculos que dificultan la libertad de ejercicio profesional. Pero esta ardua tarea, iniciada como vimos por los beneméritos constituyentes de Cádiz, ha de chocar siempre con resistencias gremialistas hoy asidas al artículo 36 de la Constitución. Tal vez la constancia con la que nuestros textos constitucionales históricos incluyen el derecho a la opción libre de oficio o profesión esconda la permanente preocupación por un problema jamás solucionado. 
REALA-1988, núm. 239. TOLIVAR ALAS, LEOPOLDO. LA CONFIGURACION CONSTITUCIONAL DE...

REALA-1988, núm. 239. TOLIVAR ALAS, LEOPOLDO. LA CONFIGURACION CONSTITUCIONAL DE... 